Documents de travail du Département des Affaires économiques de l'OCDE No. 741

\title{
Comment réformer \\ le système fiscal belge afin de renforcer l'expansion économique
}


Organisation de Coopération et de Développement Économiques

Organisation for Economic Co-operation and Development

18-Dec-2009

DEPARTEMENT DES AFFAIRES ECONOMIQUES

Français - Or. Anglais

COMMENT RÉFORMER LE SYSTÈME FISCAL BELGE AFIN DE RENFORCER L'EXPANSION ÉCONOMIQUE

DEPARTEMENT DES AFFAIRES ÉCONOMIQUES DOCUMENT DE TRAVAIL No 741

Par Jens Høj

Les Documents de travail de Département des Affaires économiques sont disponibles sur notre site Internet: www.oecd.org/eco/documentsdetravail 


\section{RESUMÉ/ABSTRACT}

\section{Comment réformer le système fiscal belge afin de renforcer l'expansion économique}

Les éléments constitutifs du système fiscal belge influe sur le processus de croissance par des canaux différents et à des degrés divers. Les impôts sur la consommation sont parmi ceux qui faussent le moins la croissance et il est tout à fait possible, en Belgique, d'exploiter davantage cette source de recettes fiscales. La taxation différenciée des instruments d'épargne fausse les décisions d'investissement, entravant le redéploiement des capitaux vers leur emploi le plus productif. Cependant, les impôts qui occasionnent le plus de distorsions sont ceux qui frappent le revenu du travail, en raison de leur impact sur les décisions des travailleurs en matière d'emploi. Conscientes de cela, les autorités belges ont cherché à alléger la fiscalité du travail. Cette dernière demeure cependant lourde en comparaison des autres pays, en raison de nombreuses exonérations, qui réduisent les bases d'imposition et nécessitent donc, pour compenser, des taux d'impôt plus élevés. Afin d'améliorer les perspectives des différents groupes sur le marché du travail, on a eu recours largement à des subventions salariales et des réductions de cotisations de sécurité sociale, créant ainsi un système complexe, souvent mal ciblé et visant parfois des objectifs contradictoires. En fin de compte, l'interaction entre l'impôt sur le revenu des personnes physiques, les cotisations de sécurité sociale et le généreux système de prestations a créé une multitude de pièges du marché du travail qui brident l'emploi. Les nouvelles réformes fiscales sont limitées par les problèmes importants et grandissants de viabilité des finances publiques, ce qui signifie que, à moins de procéder à de fortes compressions de dépenses, ces réformes devront s'autofinancer. Pour ce faire, il faut déplacer la charge fiscale vers les sources qui créent le moins de distorsions et élargir les bases d'imposition afin de pouvoir appliquer des taux plus bas. Ce document de travail se rapporte à l'Étude économique de l'OCDE de la Belgique, 2009 (www.oecd.org/eco/etudes/belgique).

Codes JEL : L41; L43; L50; K23.

Mots Clés : Belgique, croissance et fiscalité, décisions en faveur du marché du travail, taxes sur la consommation, assiette fiscale, taux d'imposition, cotisations de sécurité sociale, imposition des instruments d'épargne, soutenabilité budgétaire.

\section{How to reform the Belgian tax system to enhance economic growth}

Individual elements in the Belgian tax system affect the growth process through different channels and to a varying degree. Consumption taxes are among the least distortive for growth, and there is considerable scope to increase the reliance on this tax source in Belgium. The Belgian differential taxation of saving vehicles distorts investment decisions, hampering the reallocation of capital towards its most productive use. However, the most distortive Belgian taxes are on labour through their effects on workers' labour market decisions. Recognising the latter, the authorities have aimed at reducing taxation on labour. However, its level remains internationally high, reflecting numerous exemptions, which reduce tax bases and thus require higher tax rates than otherwise. To promote labour market prospects for individual groups on the labour market, wage subsidies and social security contribution reductions have been used extensively, leading to a complex system, often poorly targeted and at times subject to conflicting objectives. The end result is that the interaction between the personal income tax, the social security contributions, and the generous benefit systems has created a multitude of labour market traps which hold back employment. New tax reforms are constrained by the large and growing fiscal sustainability problem, implying that, unless substantial expenditure cuts are implemented, new tax reforms must be self-financed. This can be achieved by shifting the reliance of the tax system towards the least distortive sources and by broadening tax bases to allow lower tax rates. This Working Paper relates to the 2009 OECD Economic Survey of Belgium (www.oecd.org/eco/surveys/belgium).

JEL classification: $\mathrm{H} 20, \mathrm{H} 23, \mathrm{H} 24, \mathrm{H} 25, \mathrm{O} 16$.

Keywords: Belgium; tax and growth; labour market decisions; consumption taxes; tax bases; tax rates; social security contributions; taxation of savings vehicles; fiscal sustainability.

Copyright OECD, 2009

Application for permission to reproduce or translate all, or part of, this material should be made to: Head of Publications Service, OECD, 2 rue André Pascal, 75775 Paris Cedex 16, France. 


\section{TABLE DES MATIERES}

Comment réformer le système fiscal belge afin de renforcer l'expansion économique ................................ 5

Le système fiscal repose lourdement sur la taxation du revenu du travail ............................................. 5

Le niveau élevé d'imposition sur le revenu du travail a un impact négatif sur l'offre de travail............... 8

Le système d'impôt sur le revenu des personnes physiques est conçu de façon à être très progressif.... 8

Les cotisations de sécurité sociale pèsent lourdement sur le revenu du travail .................................... 15

Malgré l'intervention des pouvoirs publics, les pièges du marché du travail restent de taille .............. 20

Le système d'impôt sur les bénéfices des sociétés est devenu plus neutre vis-à-vis des divers types de

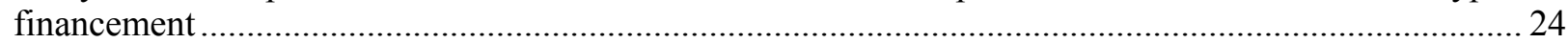

Le traitement fiscal de l'épargne varie considérablement selon les instruments ................................... 28

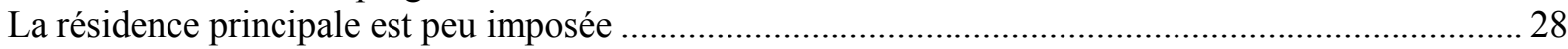

La part des impôts sur la consommation est assez faible .................................................................... 32

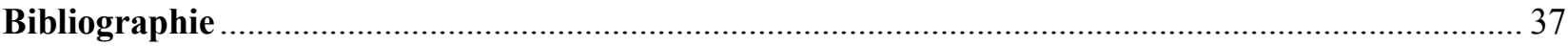

\section{Encadrés}

1. Un système d'imposition à taux uniforme pour la Belgique ..................................................... 11

2. Principales exonérations générales dans le système de sécurité sociale.................................... 16

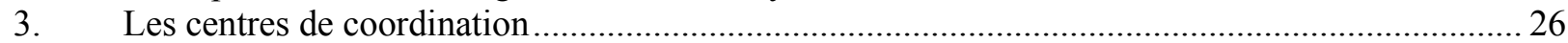

4. Recommandations pour une réforme fiscale axée sur la croissance........................................... 35

\section{Tableaux}

1. Avantages accessoires partiellement ou totalement exonérés d'impôt fournis par l'employeur... 14

2. Composition des cotisations de sécurité sociale................................................................... 16

3. Réductions des cotisations patronales de sécurité sociale et de subventions salariales.................. 17

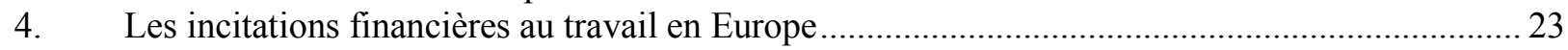

\section{Graphiques}

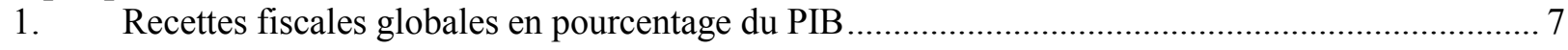

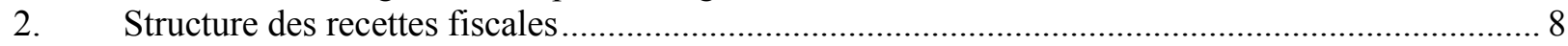

3. Taux d'imposition marginaux par type de revenu imposable ..................................................... 9

4. Taux légaux maximums d'imposition sur le revenu des personnes physiques et impôt moyen sur le revenu pour les gains moyens dans la zone de l'OCDE ........................................... 10

5. Progressivité de l'impôt sur le revenu pour les célibataires rémunérés au niveau des gains

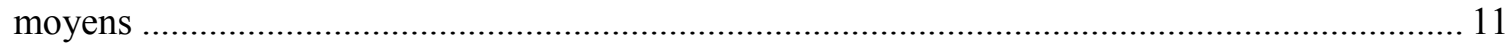

6. Taux marginaux maximums et seuil de revenu correspondant ............................................... 12

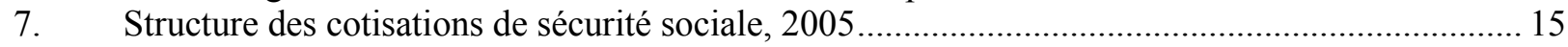

8. Perspectives d'emploi pour les jeunes travailleurs dans la zone de l'OCDE .............................. 20

9. Progressivité des impôts et nombre d'heures ouvrées................................................................ 21

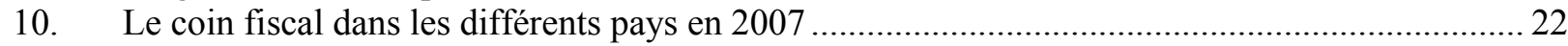


11. Taux d'imposition sur les sociétés : comparaison internationale …….......................................25

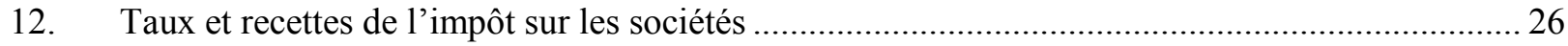

13. L'imposition effective des instruments d'épargne varie considérablement .................................2 28

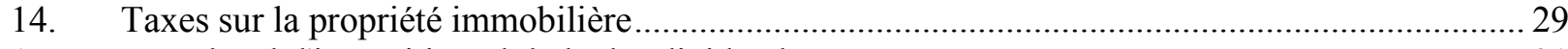

15. Taux légal d'imposition globale des dividendes......................................................................... 31

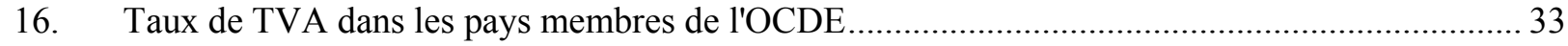

17. Productivité de la TVA dans les pays membres de l'OCDE........................................................ 34

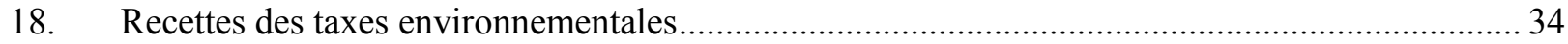

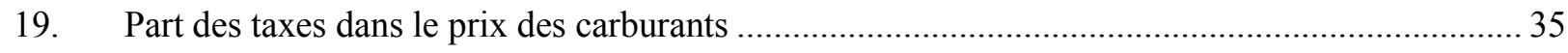


ECO/WKP(2009)82

\title{
Comment réformer le système fiscal belge afin de renforcer l'expansion économique
}

\author{
Par Jens Høj ${ }^{1}$
}

\section{Le système fiscal repose lourdement sur la taxation du revenu du travail}

1. Le présent article traite principalement de la façon dont les impôts infléchissent la croissance à travers leurs effets sur les décisions des ménages en matière d'épargne, d'offre de travail et d'investissement en capital humain, sur les décisions des entreprises concernant la production, la création d'emplois, l'investissement et l'innovation, et sur le choix des instruments d'épargne par les investisseurs. Les impôts influent sur ces décisions à la fois par leur niveau et par leur structure, ce qui signifie qu'une réforme fiscale visant à stimuler la croissance doit s'attaquer aux taux élevés d'imposition et déplacer la charge fiscale vers les sources qui créent moins de distorsions. Au total, dans le « classement des impôts en fonction de la croissance », les impôts sur le patrimoine sont ceux qui occasionnent le moins de distorsions, suivis des impôts sur la consommation, des impôts sur le revenu des personnes physiques et des impôts sur les bénéfices des sociétés.

2. Depuis le début des années 2000, les réformes fiscales en Belgique ont généralement suivi la tendance internationale, à savoir que la fiscalité devient plus favorable à la croissance, avec des allégements d'impôt sur le revenu du travail et une modernisation de la fiscalité des sociétés. Cela a contrasté avec l'évolution observée dans les années 90 , où les politiques fiscales visaient principalement à assurer la consolidation budgétaire afin de permettre l'entrée dans la zone euro ${ }^{2}$. Les réformes ont consisté d'abord à supprimer progressivement la plupart des mesures d'assainissement des finances publiques mises en place dans les années 90 (rétablissement intégral de l'indexation des tranches d'imposition et suppression de la de la contribution complémentaire de crise). Ensuite, à partir de 2002, une série de réformes a allégé les impôts sur le revenu des personnes physiques, les cotisations de sécurité sociale et les taux d'imposition des sociétés, pour un coût budgétaire global total équivalant à $1.3 \%$ du PIB. La réforme de l'impôt sur le revenu des personnes physiques a été mise en œuvre sur quatre ans, suivant quatre volets distincts (les deux premiers constituant l'essentiel de la réforme) :

1. Jens Høj est l'économiste principal dans le Bureau des Belgique et Pays-Bas à l'OCDE. Ce travail a été initialement réalisé pour l'Étude économique sur de la Belgique de l'OCDE publiée en juillet 2009 sous l'autorité du Comité d'examen des situations économiques et des problèmes de développement de l'OCDE. L'auteur remercie ses collègues de l'OCDE Andrew Dean, Robert Ford, Pierre Beynet, Tomasz Koźluk et Bert Brys pour leurs commentaires utiles ainsi que Sylvie Foucher-Hantala pour l'aide à la recherche statistique et Veronique Henriksson, Maartje Michelson et Sylvie Ricordeau pour l'assistance technique.

2. Les mesures d'assainissement ont consisté notamment à suspendre l'indexation automatique des barèmes fiscaux et à mettre en place une surtaxe de crise de $3 \%$, une cotisation spéciale de sécurité sociale et un prélèvement « de solidarité » sur les revenus de pensions (OCDE, 2004). 
- Le volet 1 a consisté à alléger la charge fiscale pesant sur le revenu du travail par i) un crédit d'impôt pour les titulaires de bas salaires ; ii) une augmentation de la déduction forfaitaire pour frais professionnels dans la tranche d'impôt la plus basse et iii) un relèvement des deuxième et troisième tranches d'imposition sur le revenu; et $i v$ ) la suppression des taux marginaux d'imposition les plus élevés.

- Le volet 2 a généralisé l'imposition individuelle et instauré la neutralité entre les styles de vie en traitant les couples mariés comme les couples non mariés.

- Le volet 3 a eu pour objectif à égaliser les déductions pour les contribuables ayant des enfants à charge.

- Le volet 4 a privilégié l'imposition favorable à l'environnement.

3. Dans le cadre du volet «valorisation du travail» de la réforme fiscale, les taux moyens d'imposition ont été abaissés dans l'ensemble du barème, mais un peu plus pour les contribuables à faible revenu, afin de renforcer l'impact positif sur les incitations à travailler. Cependant, le ciblage de cette mesure sur les travailleurs à bas salaire a provoqué un pic dans les taux marginaux d'imposition, atteignant environ $72 \%$, pour les revenus équivalant à peu près à la moitié des gains moyens (du fait de la suppression progressive de la réduction des cotisations individuelles de sécurité sociale) et un autre pic, un peu moins élevé, pour les revenus égaux à deux tiers du salaire moyen. Seuls les revenus supérieurs à un tiers et deux tiers de la rémunération moyenne ont bénéficié d'une diminution des taux marginaux, même si l'effet produit sur la redistribution des revenus a été fort limité. Les effets sur la croissance de la réforme fiscale de 2002 ne se sont sans doute pas encore fait sentir intégralement du fait que les réformes structurelles se répercutent généralement sur le chômage structurel 5 à 10 ans plus tard (Mourougane et Vogel, 2008). Des éléments d'observation indiquent que la réforme fiscale (y compris les autres mesures adoptées au cours de la première moitié des années 2000) a eu un effet positif relativement marqué sur la consommation privée, mais cet effet s'est dissipé relativement vite (Bodart et al., 2008).

4. Il n'en demeure pas moins que la charge fiscale reste parmi les plus lourdes dans la zone de l'OCDE (graphique 1). En pourcentage du PIB, les recettes tirées des cotisations de sécurité sociale et des impôts indirects sont plus élevées que dans les autres pays de l'OCDE. Cependant, le produit des impôts indirects représente une part plus faible des recettes fiscales totales que dans la plupart des autres pays de l'OCDE. De plus, le système fiscal belge repose davantage sur les recettes provenant des cotisations de sécurité sociale et des impôts indirects que ceux des autres pays de l'OCDE. Les modifications apportées à la structure fiscale par les réformes des années 2000 ont réduit les impôts sur le revenu des personnes physiques et accru la dépendance à l'égard des taxes sur les entreprises et de la TVA (graphique 2). Enfin, le taux relativement élevé de l'impôt sur les bénéfices des sociétés continue de poser problème en Belgique, même si sa neutralité du point de vue des modes de financement est plus grande que dans les autres pays. 
Graphique 1. Recettes fiscales globales en pourcentage du PIB

$2006^{1}$
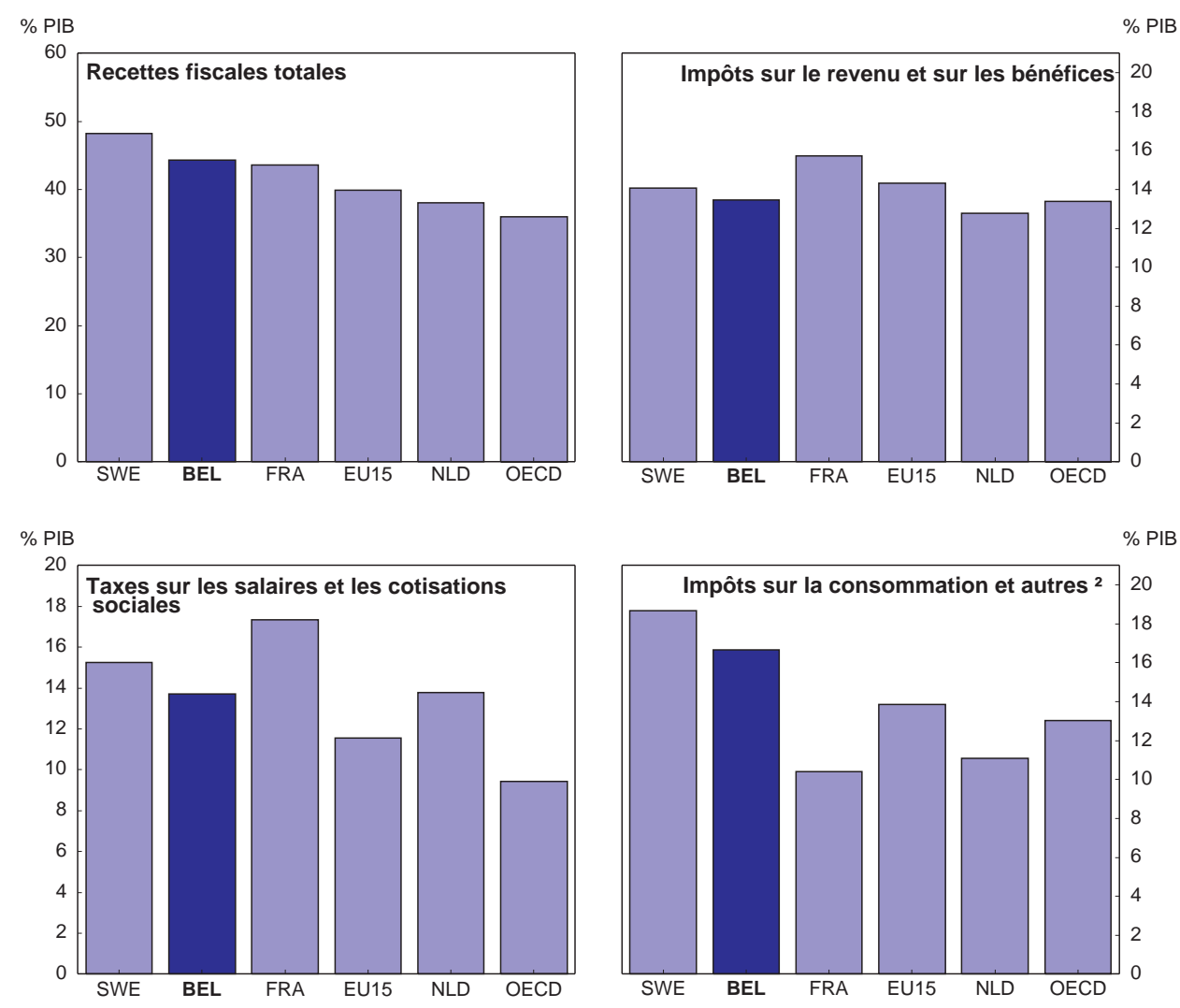

1. Ou dernière année pour laquelle des chiffres sont disponibles.

2. $\mathrm{Y}$ compris les taxes sur les produits et services et sur le patrimoine.

Source : OCDE, Base de données des statistiques de recettes publiques.

5. Ces réformes ont été mises en œuvre sous la contrainte d'assurer la viabilité des finances publiques, ce qui n'est pas encore réalisé (OCDE, 2009). Par conséquent, en l'absence de compressions de dépenses, toute réforme fiscale future devra viser principalement à être neutre du point de vue des recettes. On verra dans le présent l'article comment les réformes fiscales peuvent doper la croissance sans compromettre la viabilité budgétaire. L'article commence par montrer comment l'imposition du revenu du travail réduit l'activité et le temps de travail, puis analyse l'imposition du revenu du capital et ses effets de distorsion sur les décisions relatives à l'épargne et à l'investissement. On verra ensuite comment la fiscalité des sociétés façonne les décisions en matière de financement. Sans perdre de vue la contrainte de viabilité budgétaire, on examinera comment faire en sorte que le système fiscal repose davantage sur les impôts sur la consommation comme autre source possible de recettes, et l'article se terminera par une série de recommandations d'action. 


\section{Graphique 2. Structure des recettes fiscales}

Pourcentage des recettes fiscales totales

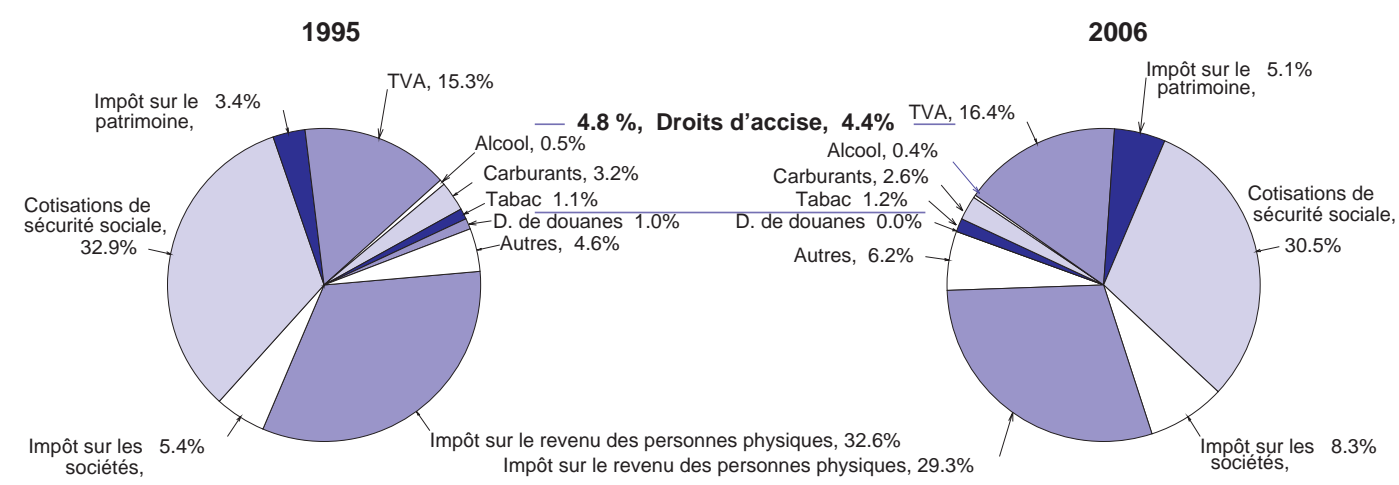

Source : OCDE, Base de données des statistiques des recettes publiques.

\section{Le niveau élevé d'imposition sur le revenu du travail a un impact négatif sur l'offre de travail}

\section{Le système d'impôt sur le revenu des personnes physiques est conçu de façon à être très progressif}

6. La Belgique a un système d'imposition sur le revenu (semi-)duale, dans lequel des taux d'imposition nominaux différents s'appliquent au revenu du travail et au revenu du capital. Le revenu salarial est soumis à une imposition progressive, suivant cinq tranches (graphique 3). Malgré la suppression de la tranche d'imposition marginale maximale dans le cadre de la réforme de 2002, le taux légal maximal de l'impôt sur le revenu salarial et le taux moyen pour un célibataire rémunéré au niveau du gain moyen restent parmi les plus élevés dans la zone de l'OCDE (graphique 4). Les autres pays ayant réduit la progression des taux de l'impôt sur le revenu, la Belgique reste l'un des pays de l'OCDE où elle est la plus forte (graphique 5). Cette progression concerne cependant, pour l'essentiel, les revenus relativement faibles puisque le taux marginal le plus élevé s'applique aux revenus qui sont inférieurs au gain annuel moyen pour les célibataires (graphiques 3 et 6$)^{3}$.

3. Les mesures fiscales prises récemment par les régions n'ont guère aidé à résoudre les problèmes d'incitation dans le système fiscal. La région flamande a opté pour une réduction forfaitaire de l'impôt sur le revenu de 125 EUR par an en 2007 pour les travailleurs à faible revenu, qui a été augmentée de 75 EUR l'année suivante avant d'être de nouveau revue à la hausse et étendue en 2009 à tous les travailleurs résidant dans les Flandres. La région wallonne a supprimé la redevance radiophonique (27.57 EUR par appareil), ce qui, encore une fois, est une mesure limitée, mais qui accroît la pression sur les autres impôts, notamment les impôts sur le revenu du travail. 
Graphique 3. Taux d'imposition marginaux par tranches de revenu imposable

2008

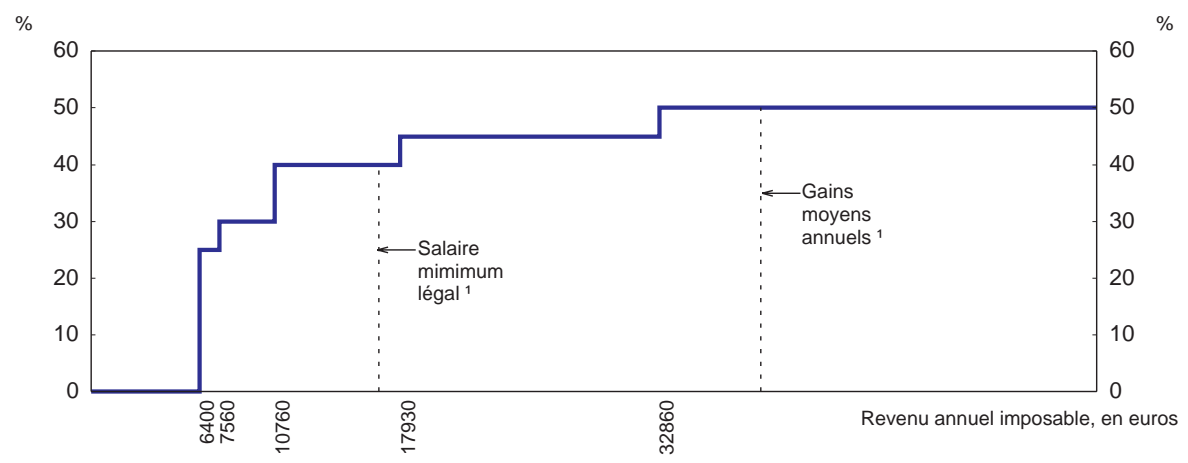

1. Le salaire minimum légal en 2008 est de 16657 EUR et la rémunération annuelle moyenne est de 38681 EUR.

Source : OCDE, Base de données des impôts sur les salaires.

7. De ce fait, un taux d'imposition marginal relativement élevé de $40 \%$ s'applique aux revenus qui dépassent de peu le salaire minimum dans de nombreux secteurs, ce qui signifie que plus de deux tiers de l'ensemble des foyers fiscaux sont assujetties à des taux marginaux de plus de $40 \%$ (Decoster et van Camp, 2005). En même temps, près de $18 \%$ de tous les foyers fiscaux ne paient pas d'impôt sur le revenu (Decoster et al., 2008). Par conséquent, en dépit de sa forte progressivité théorique, le système d'impôt sur le revenu, dans la pratique, ressemble, à bien des égards, à un régime à taux uniforme (dit « unique »), avec un abattement fiscal à la base relativement important (encadré 1). Néanmoins, plusieurs études montrent que le système combiné d'imposition sur le revenu du travail (c'est-à-dire l'impôt sur le revenu des personnes physiques et les cotisations de sécurité sociale) est progressif (Decoster et van Camp, 2005 ; Valenduc, 2006). Dans le système de sécurité sociale, la redistribution tient au fait que les ménages à faible revenu, y compris les allocataires de prestations sociales, ne paient pas de cotisations ou en paient peu et qu'il n'y a pas de plafond de revenu pour les cotisations, contrairement à ce que l'on observe dans un certain nombre d'autres pays de l'OCDE (voir plus loin) (Decoster et al., 2006). Si l'on ajoute à cela les effets des prestations sociales, le système de sécurité sociale est celui qui contribue le plus à la redistribution des revenus. La contribution de l'impôt sur le revenu des personnes physiques passe quant à elle par le biais des taux progressifs. Il convient de mentionner, toutefois, que certains éléments du système sont, de fait, régressifs. Les taux d'imposition supplémentaire sur le revenu appliqués par les communes sont en général plutôt régressifs puisque les communes riches appliquent les taux les plus bas. De même, les déductions fiscales sont généralement régressives étant donné que plus de deux tiers des catégories de revenu les plus élevées bénéficient de l'abattement sur les remboursements de crédit hypothécaire, alors que très peu de ménages en profitent dans les catégories de revenu les plus basses (Conseil supérieur des finances, 2002 ; Valenduc, 2004 ; van Cauter et van Meensel, 2006) ${ }^{4}$.

4. Les abattements fiscaux les plus régressifs sont ceux accordés pour les assurances collectives et les parts octroyées aux salariés, où les deux déciles de revenu les plus élevés représentent environ $85 \%$ des coûts budgétaires correspondants (Conseil supérieur des finances, 2002 ; Valenduc, 2004 ; van Cauter et van Meensel, 2006). 


\section{$\mathrm{ECO} / \mathrm{WKP}(2009) 82$}

Graphique 4. Taux légaux maximums d'imposition sur le revenu des personnes physiques et impôt moyen sur le revenu pour les gains moyens dans la zone de l'OCDE

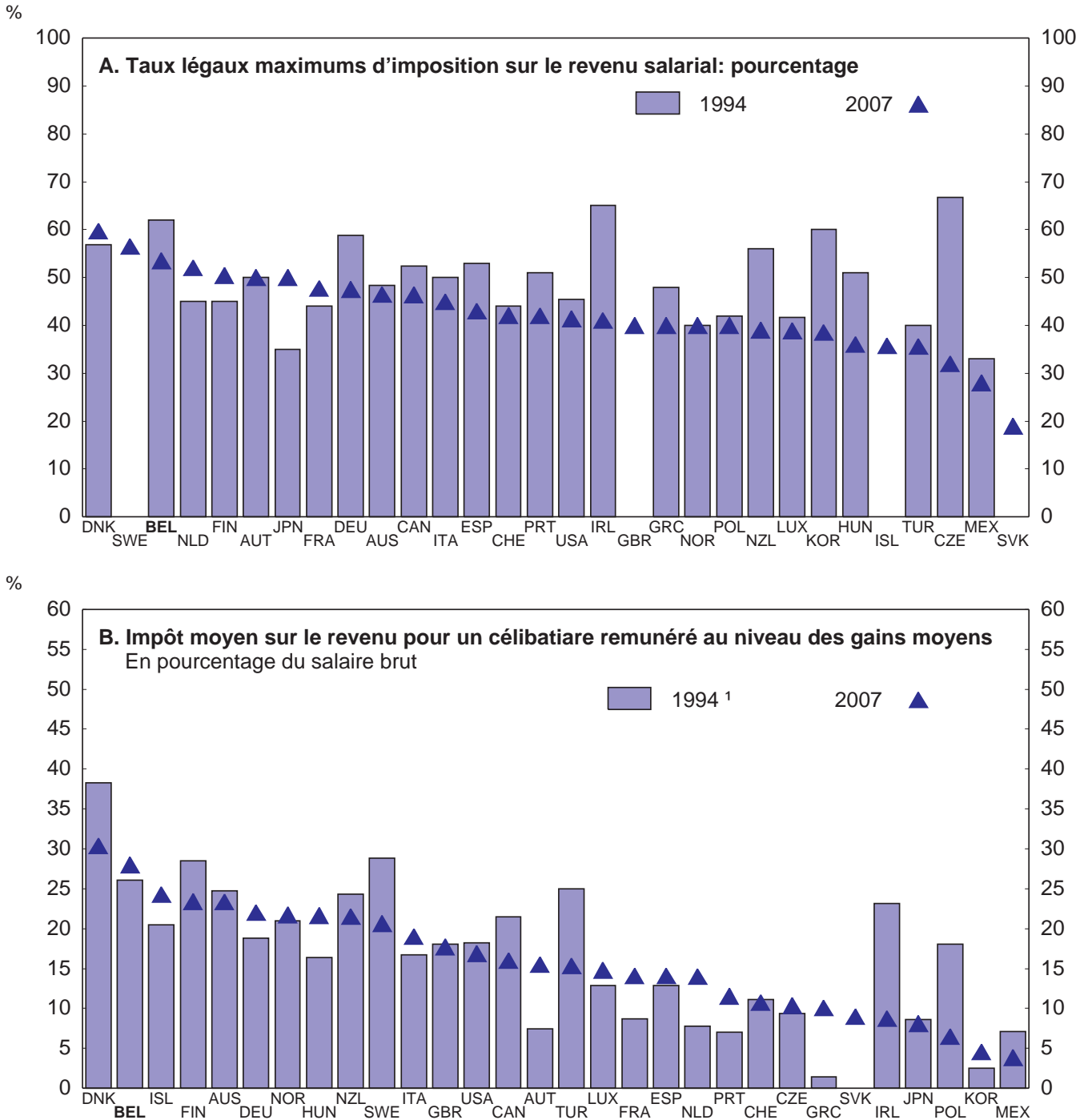

1. 1995 pour la Hongrie, la Pologne et la Corée, 1996 pour l'Australie. Les chiffres pour la Belgique tiennent compte de la surtaxe locale qui s'ajoute à l'impôt sur le revenu des personnes physiques.

Source : OCDE, Base de données fiscales. 
ECO/WKP(2009)82

\section{Graphique 5. Progressivité de l'impôt sur le revenu pour les célibataires rémunérés au niveau des gains moyens ${ }^{1}$}

Indice croissant avec la progressivité

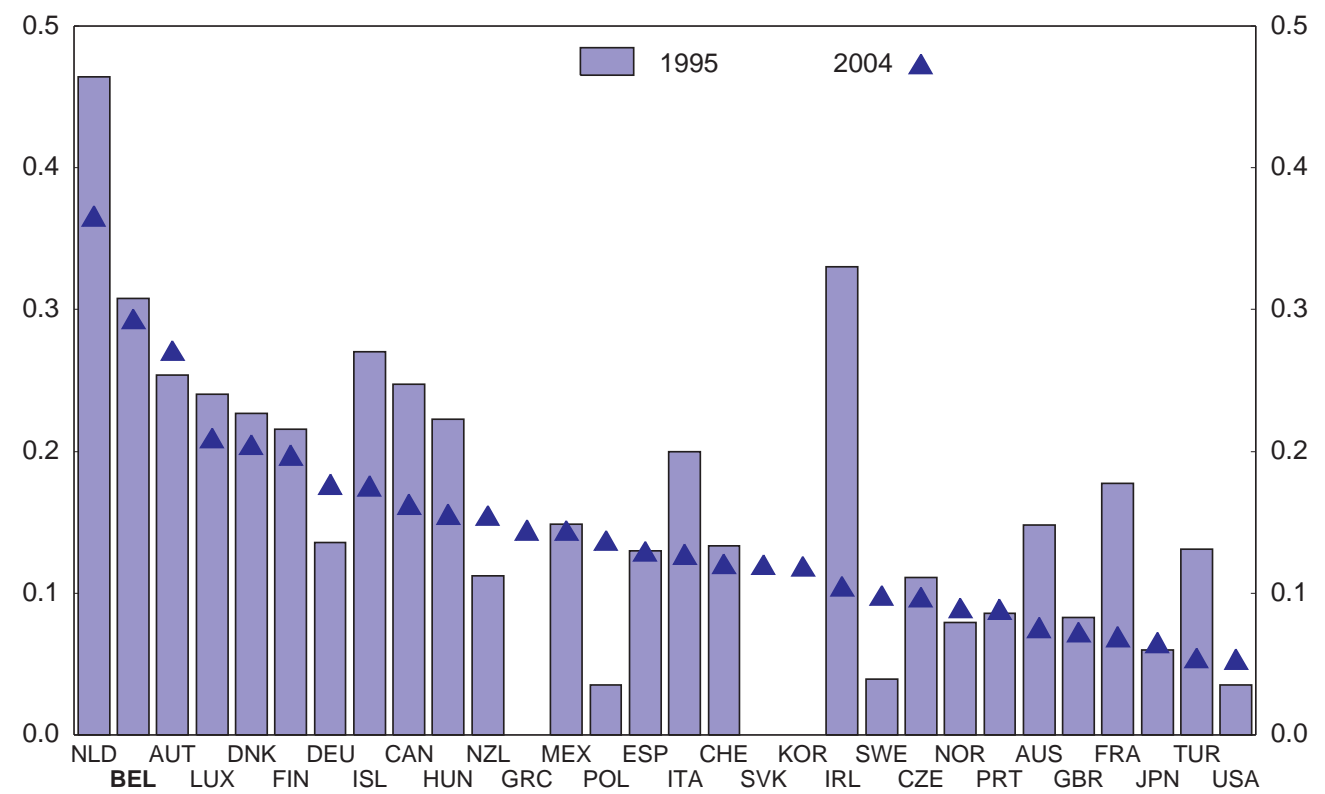

1. La mesure de la progressivité utilisée est la différence entre les taux marginal et moyen d'imposition sur le revenu des personnes physiques, divisée par un moins le taux moyen d'imposition sur le revenu des personnes physiques, pour un célibataire rémunéré au niveau du salaire moyen. Des valeurs plus élevées indiquent une progressivité plus forte.

Source : OCDE (2009), Objectif croissance.

\section{Encadré 1. Un système d'imposition à taux uniforme ou « unique »pour la Belgique}

Le système d'impôt sur le revenu des personnes physiques qui crée le moins de distorsions dans les décisions d'offre de travail est un système à taux uniforme, puisqu'il ne crée pas de contre-incitations à augmenter le nombre d'heures de travail et favorise l'entrepreneuriat et la prise de risque correspondante, renforçant de ce fait les gains de productivité. Dans le contexte belge, l'adoption de ce système, mais avec un généreux abattement fiscal à la base, aurait à peu près le même effet, globalement, sur la répartition du revenu que le régime actuel. On notera toutefois que la répartition des revenus en serait affectée, notamment pour les particuliers, et que l'introduction d'un tel système dans un État providence est une tâche particulièrement difficile. En outre, à long terme, le passage à un système à taux uniforme (neutre du point de vue des recettes) atténuerait les modifications éventuelles de la répartition du revenu car les effets les plus importants sur les incitations à l'activité seraient ressentis par les ménages à faible revenu. Decoster et al., (2008) estiment que la mise en place d'un système d'imposition uniforme, neutre du point de vue des recettes, et le maintien des abattements à la base permettraient d'appliquer un taux uniforme de $37 \%$ et d'accroître l'offre de main-d'œuvre (en équivalent temps plein) de $2 \%$, tandis que la suppression de toutes les exonérations permettrait d'avoir un système d'imposition neutre du point de vue des recettes avec un taux uniforme de $26 \%$ (Decoster et al., 2008). II est plus facile d'avoir un taux uniforme plus bas dans un cadre neutre en termes de recettes si d'autres exemptions sont levées, comme celles qui sont accordées pour les prêts hypothécaires. Cela aurait pour avantage supplémentaire de résoudre certains des problèmes de répartition. Indépendamment des effets positifs sur les incitations à l'activité, cette réforme permettrait aussi d'abaisser les coûts administratifs et de respect des obligations fiscales. 
Graphique 6. Taux marginaux maximums et seuil de revenu correspondant

2007
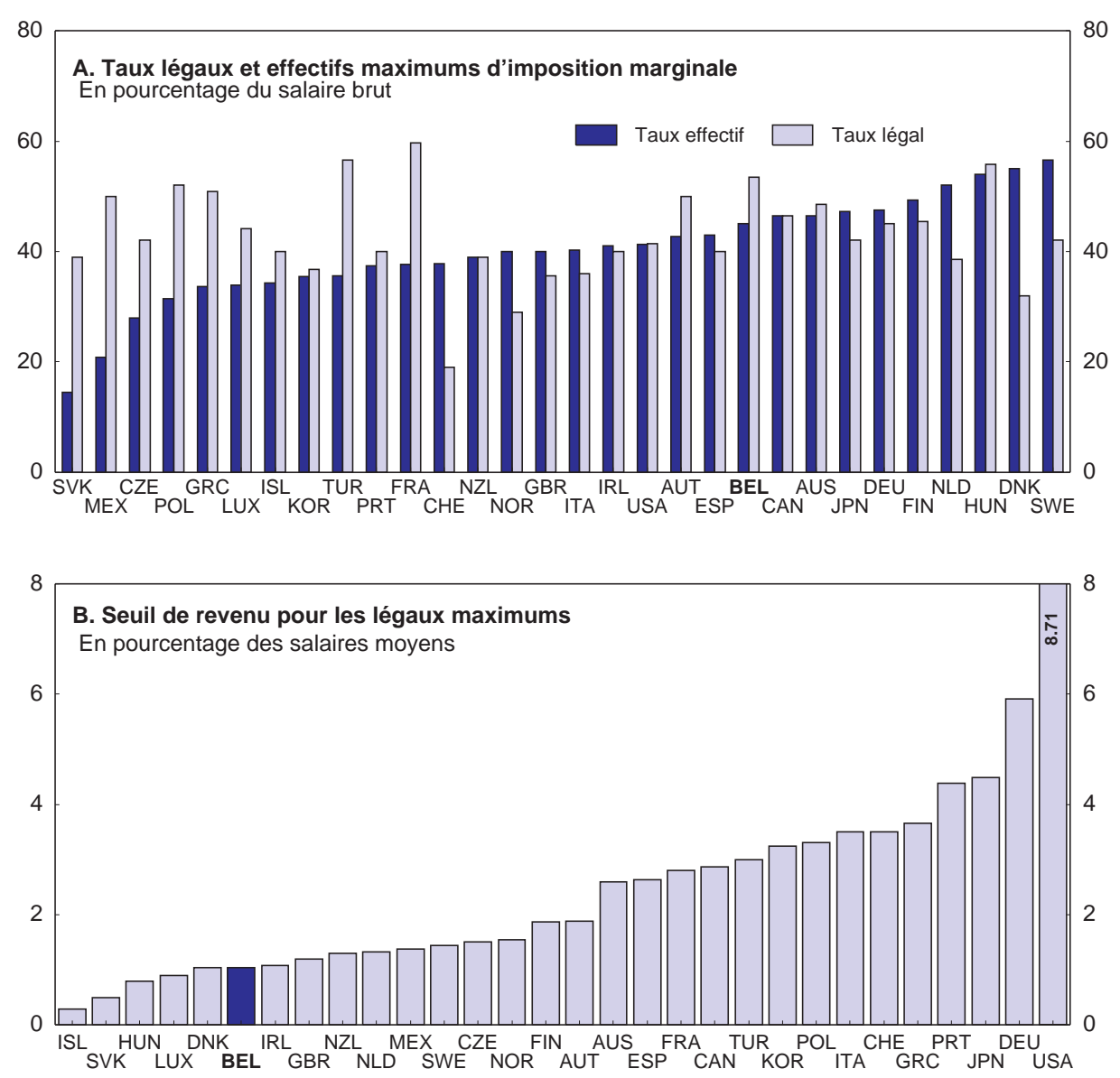

Source : OCDE, Base de données fiscales.

8. Le recours aux allégements fiscaux est généralisé et rétrécit l'assiette de l'impôt, obligeant à appliquer des taux d'imposition plus élevés. La principale composante est l'allégement structurel, qui n'est pas considéré comme une dépense fiscale en Belgique en raison de son caractère général, comme la déductibilité des paiements d'intérêt hypothécaires. Les dernières données disponibles depuis 2003 montrent que le manque à gagner de recettes résultant de l'allégement structurel représente environ $6 \% \mathrm{du}$ $\mathrm{PIB}$, ce qui équivaut à plus d'un tiers de l'ensemble des impôts sur le revenu des personnes physiques et bien plus que les dépenses fiscales (OCDE, 2006 ; Chambre des Représentants de Belgique, 2007). Cela s'explique pour près de moitié par l'abattement fiscal à la base. On peut citer comme autres allégements importants les déductions liées à l'exercice d'un emploi (environ $1 \%$ du PIB) et à visée sociale, comme diverses déductions familiales et pour enfant à charge, qui occasionnent un manque à gagner de recettes fiscales de près de $1 \%$ du PIB, ainsi que le "quotient conjugal" (le système de partage de la charge fiscale entre les conjoints à l'avantage essentiellement des ménages à revenu unique) qui entraîne une perte de $0.3 \%$ du PIB. Ce type d'allégement d'impôt remplace d'autres dépenses destinées à visée sociale, ce qui signifie que le supprimer ne réduirait peut-être pas, en soi, la charge fiscale globale étant donné qu'il faudrait, en compensation, augmenter les dépenses sociales. Cependant, le principal problème que pose cet 
allégement structurel dans un système fiscal fortement axé sur la redistribution des revenus réside dans le fait qu'il est mal ciblé. Il suffirait de mieux cibler le dispositif en remplaçant l'allégement d'impôt à visée sociale par des dépenses sociales ciblées pour accroître les recettes fiscales dans une proportion supérieure à l'augmentation nécessaire des dépenses sociales, ce qui permettrait de réduire légèrement les taux d'imposition. Pour élargir la base d'imposition, il faudrait donc que le gouvernement remplace l'allégement fiscal structurel par des mesures plus ciblées afin de poursuivre ses objectifs sociaux.

9. Les dépenses fiscales, qui sont bien moins étendues que l'allégement fiscal structurel, représentent près de $3 \%$ du PIB, ce qui paraît élevé par rapport à beaucoup d'autres pays de l'OCDE. Dans les années 2000, les dépenses fiscales ont pris de plus en plus d'importance, par exemple avec les déductions de l'impôt sur le revenu des personnes physiques pour les investissements dans le logement et dans les équipements économes en énergie et l'application de taux de TVA réduits aux services à forte intensité de main-d'œuvre en 2002. Du point de vue de la croissance, le principal problème que posent les dépenses fiscales est qu'elles rétrécissent les bases d'imposition et obligent à appliquer des taux d'imposition plus élevés. Par ailleurs, du point de vue de la redistribution des revenus, elles sont mal ciblées - les écrivains et d'autres artistes, par exemple, bénéficient d'un régime fiscal préférentiel avec un taux d'imposition maximal de $15 \%$ sur les 50000 premiers euros. De surcroit, certaines dépenses fiscales n'ont pas vraiment de finalité économique ; c'est le cas notamment des comptes d'épargne exonérés d'impôt (voir plus loin). Réduire les dépenses fiscales au niveau moyen observé dans les trois pays voisins $(1 \% \mathrm{du} \mathrm{PIB})$ pourrait en fait créer des recettes nettes supplémentaires équivalant à environ $1 \% \mathrm{du}$ PIB, même si l'on suppose qu'il faudrait augmenter d'autant les dépenses au titre de mesures sociales et de redistribution des revenus. Les calculs de modèle fiscal réalisés par le Ministère des finances indiquent qu'une réduction de moitié des dépenses fiscales pourrait financer une diminution du taux moyen d'imposition de près de 1 point (compte non tenu des effets dynamiques) et conduire à une légère amélioration de la répartition du revenu après impôt. Les dépenses fiscales doivent donc être réduites, de façon à élargir l'assiette de l'impôt, ce qui permettra d'appliquer des taux plus bas sans éroder les recettes fiscales.

10. Les multiples tranches d'imposition et le grand nombre de déductions fiscales rendent le système belge d'impôt sur le revenu des personnes physiques plus complexe que ceux de beaucoup d'autres pays, et les coûts administratifs et de respect des obligations fiscales sont aussi plus lourds que dans la plupart des pays de l'OCDE (OCDE, 2009). De plus, le niveau élevé des taux marginaux d'imposition réduit les incitations au travail, comme on le verra plus loin. Qui plus est, une étude de l'OCDE met en évidence un impact négatif sur la productivité, via l'entrepreneuriat, car ces taux élevés limitent la prise de risque par les individus, en particulier dans les branches d'activité ayant un fort potentiel de création d'entreprises (Johannson et al., 2008). Un autre effet défavorable sur la croissance tient au fait que des taux élevés d'imposition marginale contribuent au faible taux de rendement privé attendu des investissements en capital humain, ce qui, à moyen terme, se répercute de façon négative sur la qualité de l'offre de main-d'œuvre (Hoj, 2007 ; Oliveira Martins et al., 2007).

11. Avec un revenu du travail aussi lourdement taxé, les avantages accessoires non imposables sont fort intéressants pour les employeurs comme pour les salariés (tableau 1). Au total, les avantages accessoires représentent environ $20 \%$ des coûts salariaux dans le secteur privé et $10 \%$ seulement de la population active n'en bénéficient pas (Conseil supérieur des finances, 2007). Ces privilèges fiscaux sont sans doute largement utilisés lorsque les taux marginaux d'imposition sont élevés, d'où une augmentation des dépenses fiscales. En outre, un recours massif à ces solutions, comme dans le cas du demi-million estimé de voitures de société, peut être incompatible avec la réalisation d'autres objectifs gouvernementaux tels que la lutte contre les émissions de $\mathrm{CO}_{2}$. A titre d'exemple, plus de trois quarts des voitures de société sont équipées de moteurs diesel, contre moins de la moitié des véhicules privés. 
12. Le système d'impôt sur le revenu des personnes physiques a besoin d'être réformé, compte tenu des effets bénéfiques sur l'expansion économique que peuvent avoir un élargissement de l'assiette fiscale et un abaissement des taux. Cependant, pour respecter les objectifs d'égalité des revenus dans la société belge, il faut mettre en œuvre une réforme qui élimine certaines des tranches d'impôt sur le revenu et augmente les tranches restantes suffisamment pour que seule une part relativement faible de la population soit assujettie aux taux marginaux les plus élevés. En outre, le taux marginal le plus élevé doit être réduit afin d'augmenter le nombre d'heures de travail, tandis que le taux moyen doit être abaissé afin d'encourager l'activité. En l'absence de compressions de dépenses, ces réformes devront s'opérer dans un cadre neutre du point de vue des recettes, ce qui souligne la nécessité d'étendre la base d'imposition en supprimant les exonérations. L'on fait souvent valoir que des réformes de ce type ont un coût budgétaire important. Cependant, des estimations statiques semblent indiquer que la suppression du taux d'imposition marginal le plus élevé entraînerait une perte de recettes de moins de 1/4 pour cent du PIB et qu'avec une réduction de 1 point du taux d'imposition moyen, le manque à gagner serait encore plus faible.

Tableau 1 Avantages accessoires partiellement ou totalement exonérés d'impôt fournis par l'employeur

\begin{tabular}{|c|c|c|}
\hline & Nature de l'exonération & Conditions supplémentaires \\
\hline \multicolumn{3}{|l|}{ Exonération partielle } \\
\hline $\begin{array}{l}\text { Usage privé de voitures de } \\
\text { société (y compris pour les trajets } \\
\text { domicile-travail) }\end{array}$ & $\begin{array}{l}\text { Seuls les } 5000 \text { ou } 7500 \text { premiers } \mathrm{km} \text {, selon la } \\
\text { longueur du trajet quotidien domicile-travail, } \\
\text { sont imposables }\end{array}$ & $\begin{array}{l}\text { L'employeur doit payer une cotisation } \\
\text { au système de sécurité sociale, } \\
\text { calculée en fonction du volume de } \mathrm{CO}_{2} \\
\text { émis par la voiture de société }\end{array}$ \\
\hline Stock options & $\begin{array}{l}\text { Un taux d'imposition favorable de } 15 \% \\
\text { s'applique lors de l'émission, ce qui signifie } \\
\text { que les gains en capital sont exonérés d'impôt } \\
\text { et que les pertes en capital ne peuvent pas } \\
\text { être compensées dans l'évaluation de l'impôt. }\end{array}$ & $\begin{array}{l}\text { Si la stock option peut être exercée } \\
\text { dans un délai de } 5 \text { ans à compter de } \\
\text { l'émission, un taux d'imposition plus } \\
\text { élevé est appliqué. }\end{array}$ \\
\hline Repas & $\begin{array}{l}\text { Généralement exonérés d'impôt lorsqu'ils sont } \\
\text { fournis dans des restaurants d'entreprise ou } \\
\text { achetés à l'aide de tickets restaurant } \\
\text { ("chèques-repas") }\end{array}$ & \\
\hline $\begin{array}{l}\text { Ordinateurs et connexions à } \\
\text { I'Internet }\end{array}$ & & $\begin{array}{l}\text { Achat d'un ordinateur à un prix } \\
\text { inférieur à celui du marché par le biais } \\
\text { de l'employeur }\end{array}$ \\
\hline Prêts à taux préférentiel & $\begin{array}{l}\text { Imposition partielle de la différence entre le } \\
\text { taux appliqué et le taux du marché }\end{array}$ & \\
\hline Logement & $\begin{array}{l}\text { Imposé en fonction de la valeur cadastrale du } \\
\text { bien, qui est fixée en-dessous des valeurs du } \\
\text { marché }\end{array}$ & \\
\hline \multicolumn{3}{|l|}{ Meubles et électricité } \\
\hline Services domestiques & & $\begin{array}{l}\text { Personnel de maison, chauffeurs etc., } \\
\text { y compris les rémunérations et les } \\
\text { avantages en nature, comme la } \\
\text { nourriture et le logement. }\end{array}$ \\
\hline \multicolumn{3}{|l|}{ Exonération totale } \\
\hline Cadeaux à caractère social & $\begin{array}{l}\text { Cadeaux de mariage, de naissance, } \\
\text { assurance maladie complémentaire, utilisation } \\
\text { de crèches ou garderies de l'entreprise, } \\
\text { abonnements, billets pour des manifestations } \\
\text { culturelles etc. }\end{array}$ & $\begin{array}{l}\text { L'exonération est accordée dans la } \\
\text { limite d'un plafond légal relativement } \\
\text { bas. }\end{array}$ \\
\hline Souscriptions & $\begin{array}{l}\text { Régimes de retraite complémentaire; } \\
\text { assurances diverses contre la perte de revenu, } \\
\text { comme l'assurance vie et l'assurance } \\
\text { invalidité. }\end{array}$ & $\begin{array}{l}\text { Le revenu provenant de ces régimes } \\
\text { est intégralement imposable. }\end{array}$ \\
\hline Eco-chèques & $\begin{array}{l}\text { Exonérés d'impôts et de cotisations de } \\
\text { sécurité sociale }\end{array}$ & $\begin{array}{l}\text { Les chèques peuvent être utilisés } \\
\text { uniquement pour l'achat de certains } \\
\text { produits et services écologiques tels } \\
\text { que des arbres, des toilettes à chasse } \\
\text { d'eau écologique etc. }\end{array}$ \\
\hline
\end{tabular}

Source : Communication des autorités belges. 


\section{Les cotisations de sécurité sociale pèsent lourdement sur le revenu du travail}

13. Les cotisations patronales à l'assurance chômage et aux régimes d'assurance couvrant les maladies professionnelles et les accidents du travail ont été progressivement réduites. Ce progrès a cependant été compensé par des majorations d'autres cotisations et, au total, les cotisations restent élevées en comparaison des autres pays (graphique 7). Il existe aussi une cotisation spéciale de sécurité sociale, qui est prélevée sur la base du revenu imposable net des ménages et s'applique à toutes les personnes ayant un emploi. Cette cotisation spéciale diffère de la cotisation ordinaire pour les salariés du fait qu'elle est assortie de taux nominaux décroissants et d'un plafond de revenu. Elle n'en est pas moins globalement progressive dans la mesure où une très large tranche de revenu en est exonérée, même si, au-delà, les taux appliqués sont effectivement régressifs (van Cauter et van Meensel, 2006) ${ }^{5}$. Au total, les cotisations de sécurité sociale représentent près de $48 \%$ des gains salariaux bruts, dont 13 points sont payés par les salariés (tableau 2).

Graphique 7. Structure des cotisations de sécurité sociale, 2005

Cotisations de sécurité sociale pour un travailleur célibataire sans enfants rémunéré à $100 \%$ du salaire moyen, Pourcentage du salaire brut

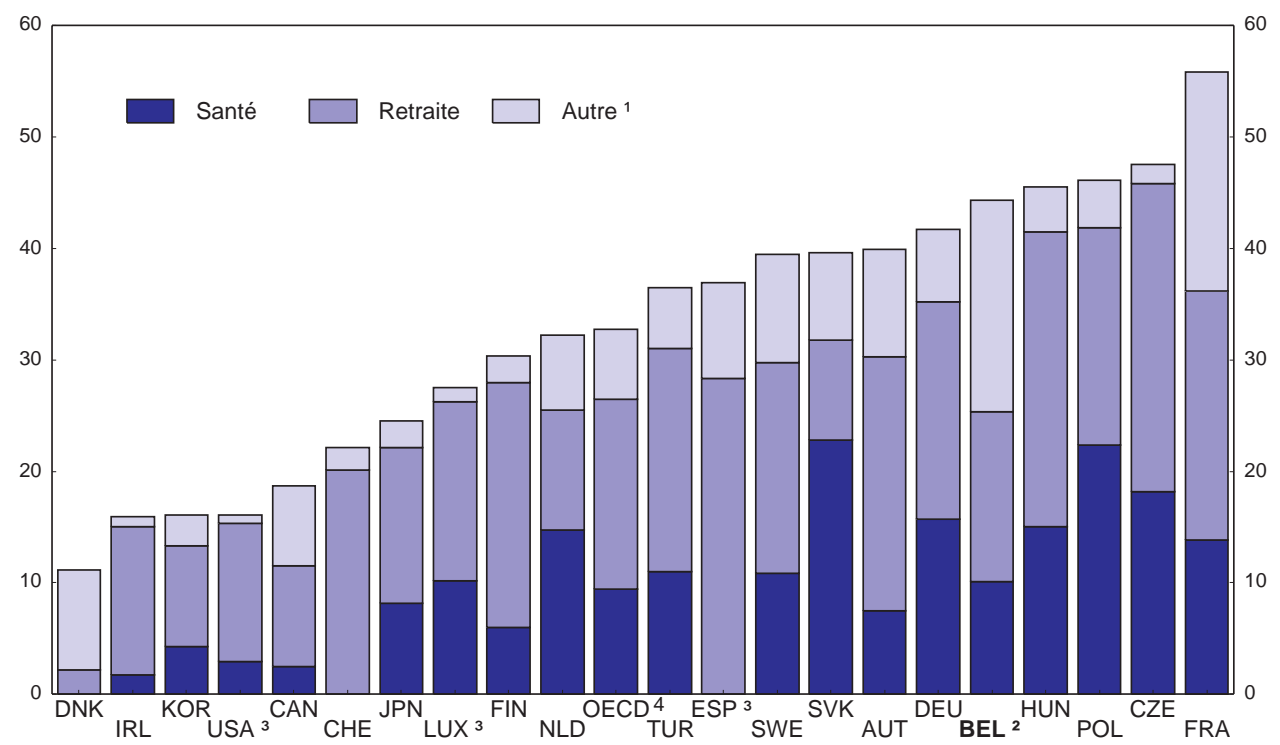

1. La catégorie " autre » comprend principalement les assurances chômage, maladies professionnelles et les accidents du travail.

2. La catégorie « autre » comprend les allocations familiales $(6 \%)$ et la modération salariale $(6.6 \%)$.

3. La catégorie « retraite » comprend l'invalidité. Pour l'Espagne, la santé est également incluse.

4. Moyenne pour les pays indiqués à l'exception du Luxembourg, de l'Espagne et des États-Unis.

Source : OCDE (2007), Perspectives de l'emploi.

5. Les ménages dont le revenu imposable net est inférieur à 18592 EUR par an ne paient pas cette cotisation spéciale. Pour les 2500 EUR suivants, le taux est de $9 \%$. Par la suite, un taux de $1.3 \%$ s'applique aux revenus inférieurs à 60162 EUR. Au-delà de ce niveau, la cotisation maximale est fixée à 731 EUR. 
Tableau 2. Composition des cotisations de sécurité sociale

Pourcentage des salaires

\begin{tabular}{lccr}
\hline & Salarié & Employeur & Total \\
\hline & & & \\
Assurance chômage & 0.87 & 3.16 & 4.03 \\
$\begin{array}{l}\text { Soins de santé et assurance maladie } \\
\text { Assurance couvrant les maladies } \\
\text { professionnelles et les accidents du travail }\end{array}$ & 4.70 & 6.15 & 10.85 \\
$\begin{array}{l}\text { Retraites } \\
\text { Allocations familiales et allocations de garde }\end{array}$ & 7.50 & 1.31 & 1.31 \\
d'enfants & & 8.86 & 16.36 \\
$\begin{array}{l}\text { Services de placement, fermetures d'entreprise } \\
\text { et congé d'études }\end{array}$ & & 7.05 & 7.05 \\
Modération salariale & & 0.43 & 0.43 \\
Total & 13.07 & 34.55 & 47.59 \\
\hline
\end{tabular}

Source : OCDE (2009), Les impôts sur les salaires (à paraître).

14. Malgré des taux élevés de cotisations de sécurité sociale, le degré d'autofinancement du système ne dépasse pas environ $72 \%$ actuellement et, avec le vieillissement de la population, il tombera certainement aux alentours de $60 \%$ en 2040 (Decoster et al., 2006). La baisse du degré d'autofinancement s'explique par les exonérations générales (encadré 2) et par l'adoption de mesures visant à stimuler l'emploi de certains groupes sur le marché du travail, qui contribuent toutes aussi à accroître la complexité du système.

\section{Encadré 2. Principales exonérations générales dans le système de sécurité sociale}

- Les retraités paient des cotisations réduites, composées d'une cotisation de solidarité pouvant représenter jusqu'à $2 \%$ sur les pensions les plus élevées et d'une cotisation de $3.55 \%$ à l'assurance maladie.

- Les bénéficiaires de prestations d'invalidité et les personnes bénéficiant d'allocations de retraite anticipée dans le cadre d'une convention collective paient une cotisation réduite de $3.5 \%$ au régime de pensions.

- Les chômeurs ne paient pas de cotisations de sécurité sociale sur leurs prestations (van Cauter et van Meensel, 2006).

- Les travailleurs indépendants paient des cotisations de sécurité sociale régressives. Le taux est de $19.65 \%$ sur les 47203 premiers euros de revenu, après quoi il tombe à $14.16 \%$ jusqu'à 69568 EUR. II n'y a pas de cotisations à payer sur les revenus supérieurs à ce niveau.

15. De nombreuses réductions de cotisations patronales de sécurité sociale et de subventions salariales ont été mises en place afin d'améliorer les perspectives de certains groupes sur le marché du travail - une politique qui donne de bons résultats dans la mesure où, en l'absence de ces mesures, il y aurait eu quelque 90000 emplois de moins dans le secteur des entreprises (Bureau fédéral du plan, 2006) (tableau 3). Les principaux éléments sont les suivants :

- Une réduction générale de toutes les cotisations patronales de sécurité sociale.

- Des réductions de cotisations patronales de sécurité sociale pour les anciens chômeurs de longue durée, les jeunes travailleurs et les séniors, ainsi que les travailleurs employés dans des entreprises en cours de restructuration. 
ECO/WKP(2009)82

Tableau 3. Réductions des cotisations patronales de sécurité sociale et de subventions salariales

\begin{tabular}{|c|c|}
\hline Cotisations patronales de sécurité sociale & Mesures \\
\hline Réduction générale & $\begin{array}{l}\text { Une réduction générale de } 400 \text { EUR sur les cotisations de } \\
\text { sécurité sociale, qui profite à tous les salariés. Par ailleurs, } \\
\text { des réductions supplémentaires sont accordées pour les } \\
\text { titulaires de bas salaires (moins de } 5870 \text { EUR par trimestre) } \\
\text { et les titulaires de salaires élevés (plus de } 12000 \text { EUR par } \\
\text { trimestre). }\end{array}$ \\
\hline \multicolumn{2}{|l|}{ Réductions de deuxième niveau ${ }^{1}$} \\
\hline Chômeurs de longue durée (Plan Activa) & 400-1000 EUR (durée limitée) \\
\hline Jeunes de moins de 26 ayant un bas salaire & 400 EUR (jusqu'à l'âge de 26 ans) \\
\hline $\begin{array}{l}\text { Premières embauches pour les nouvelles } \\
\text { entreprises }\end{array}$ & 400 EUR (durée limitée) \\
\hline Travailleurs âgés (plus de 50 ans) & 50-800 EUR (augmente avec l'âge). \\
\hline Entreprises en restructuration ${ }^{2}$ & Réductions trimestrielles de sécurité sociale (durée limitée) \\
\hline \multicolumn{2}{|l|}{ Réductions de troisième niveau } \\
\hline Travailleurs de $18-29$ ans ayant un bas salaire & 300-30 EUR (diminue avec l'âge). \\
\hline Subventions salariales & (Coût en $2008: 2.6$ milliards EUR) \\
\hline Activités sans but lucratif (Social Maribel) & $\begin{array}{l}\text { Par personne (système de sécurité sociale) } \\
\text { ( } 0.6 \text { milliard EUR) } \\
\text { Par personne (système de sécurité sociale) }\end{array}$ \\
\hline Chômeurs de longue durée (Plan Activa) & (0.3 milliard EUR) \\
\hline $\begin{array}{l}\text { Travailleurs peu rémunérés dans de petites } \\
\text { entreprises }\end{array}$ & Par personne (région wallonne) (0.02 milliard EUR) \\
\hline Personnes travaillant de nuit et en équipe ${ }^{3,4}$ & Au pro rata (administration fédérale) (0.7 milliard EUR) \\
\hline Chercheurs du secteur privé $e^{4,5}$ & Au pro rata (administration fédérale) (0.07 milliard EUR) \\
\hline $\begin{array}{l}\text { Jeunes travailleurs à bas salaire ayant des } \\
\text { activités sans but lucratif }\end{array}$ & Par personne (système de sécurité sociale) \\
\hline Prime à l'embauche de travailleurs âgés ${ }^{6}$ & $\begin{array}{l}\text { Versement échelonné par personne (région flamande) } \\
(0.03 \text { milliard EUR) }\end{array}$ \\
\hline Subvention générale & Au pro rata (administration fédérale) (0.2 milliard EUR) \\
\hline Chèques emploi-service & Système de sécurité sociale ( 0.7 milliard EUR) \\
\hline
\end{tabular}

1. Ces réductions s'excluent généralement l'une l'autre.

2. Réductions collectives du temps de travail, réorganisation de la semaine de travail sur 4 jours, plans de restructuration pour les entreprises en difficulté.

3. Couvrent les personnes qui font des heures supplémentaires, travaillent de nuit et en équipe. Mise en place progressivement avec le relèvement par étapes du taux nominal, porté de $1 \%$ en 2003 à $10.7 \%$ en 2007 . Dans le cadre de l'accord salarial 2009-10, le taux sera encore relevé et passera à $15.6 \%$ le 1er juin 2009.

4. Octroyée sous forme de réduction de la retenue fiscale à la source sur le revenu des personnes physiques que les entreprises transfèrent à l'État.

5. En 2008, il y a eu une harmonisation de l'exonération (partielle) de paiement de la retenue fiscale à la source sur les salaries des chercheurs, le taux maximum de $65 \%$ s'appliquant à toutes les catégories de chercheurs.

6. Les autorités flamandes ont augmenté en 2009 la prime payée aux travailleurs de plus de 50 ans qui prennent un nouvel emploi et la prime (de 500 EUR supplémentaires) payée aux entreprises qui les emploient.

Source : Stockman (2007), "Wage and age related employers' SSC cuts and wage subsidies in the 2007 vintage of HERMES", Bureau fédéral du plan, Document de travail, 12-07.

- Des subventions salariales, sous forme de réduction des cotisations salariales de sécurité sociale, sont accordées pour les travailleurs à bas salaire et ceux qui prennent un emploi auprès d'un nouvel employeur après avoir été licenciés par une entreprise en restructuration (licenciements collectifs). Dans la pratique, les travailleurs rémunérés au salaire minimum légal ne sont pas assujettis aux cotisations de sécurité sociale.

- Des subventions salariales, sous forme d'une réduction de la retenue fiscale à la source sur le revenu payée par les employeurs, sont accordées pour les personnes travaillant de nuit et par équipe, les chercheurs du secteur privé et un nombre limité d'heures supplémentaires. La mesure 
a été étendue dans le cadre avec l'accord salarial 2009-10 afin d'inclure la réduction générale pour compenser les effets des hausses convenues de salaire réel sur les coûts de main-d'œuvre totaux ${ }^{6}$.

16. Des réductions de cotisations n'auront probablement pas d'effet positif à long terme sur l'emploi si elles sont financées par une augmentation des impôts sur le revenu et, sur un marché du travail aussi rigide que celui de la Belgique, elles peuvent même conduire à une hausse des salaires. On peut toutefois en attendre un impact positif dans le moyen terme, selon la façon dont la réduction est conçue. En Belgique, le système est conçu de telle sorte que le pourcentage de réduction est relativement plus grand pour les travailleurs ayant un bas salaire, ce qui entraîne des effets de substitution entre les travailleurs peu rémunérés et ceux qui ont un salaire élevé. Des études économétriques montrent que les effets les plus marqués sur l'emploi s'obtiennent avec des mesures ciblées sur les jeunes travailleurs à bas salaire ou, de façon plus générale, sur les travailleurs faiblement rémunérés. Les résultats sont moins bons avec des réductions générales, et celles qui visent les travailleurs âgés et les personnes travaillant de nuit et par équipe sont les moins efficaces (Stockman, 2007). Cela tient au fait que les subventions ciblées sur les travailleurs en équipe visent essentiellement à soutenir le secteur manufacturier, où l'emploi réagit moins aux salaires que dans le secteur des services.

17. Le coût budgétaire total des réductions de cotisations de sécurité sociale et des subventions salariales s'élève à environ 6.5 milliards EUR (dont environ deux tiers sont représentés par la réduction générale des cotisations patronales) et le coût par emploi créé ou épargné varie notablement selon les mesures. Du fait du montant peu élevé des recettes fiscales procurées par les travailleur à bas salaire, le taux d'autofinancement est de $13 \%$ seulement pour les jeunes travailleurs faiblement rémunérés, légèrement plus élevé pour les subventions en faveur des personnes travaillant en équipe et d'environ $30 \%$ pour les réductions générales des cotisations de sécurité sociale et les mesures visant les travailleurs âgés. En revanche, les mesures visant les jeunes travailleurs peu rémunérés sont les plus efficaces par rapport à leur coût, avec un coût budgétaire net de 51420 EUR par emploi créé - comparable à ceux que l'on peut observer dans les autres pays (Immervoll et Pearson, 2009 ; Grubb et Martin, 2001). Par contre, la mesure la moins efficace par rapport à son coût est celle qui vise les personnes travaillant en équipe, avec un coût budgétaire net à peu près trois fois plus élevé - environ 150000 EUR ; cette mesure couvre quelque 300000 travailleurs, pour un coût budgétaire de près de 600 millions EUR, qui va presque doubler en 2009 (OECD, 2009) - ce qui soulève la question de savoir si les avantages procurés sont suffisamment importants pour justifier cette mesure.

18. Les programmes d'allégement des cotisations couvrent des groupes relativement importants. A titre d'exemple, environ $35 \%$ de tous les emplois peuvent donner lieu à une cotisation de sécurité sociale réduite pour les bas salaires, et les programmes spéciaux (pour les chômeurs difficiles à employer et l'emploi dans de nouvelles entreprises) englobent environ 5\% de l'ensemble des emplois (Stockman, 2007). Les multiples objectifs de ces programmes sont contradictoires; selon une étude économétrique, la réduction des cotisations de sécurité sociale pour les travailleurs âgés diminue les perspectives d'emploi des jeunes titulaires d'un bas salaire (Stockman, 2007). La plupart des bénéficiaires de la subvention salariale pour les personnes travaillant de nuit et en équipe se trouvent en réalité dans le

6. Du point de vue de l'employeur, la ristourne sur le paiement des retenues fiscales à la source revient à une réduction du taux des cotisations de sécurité sociale. Du point de vue de la comptabilité nationale, la différence réside dans le fait qu'une réduction n'est pas enregistrée alors que la ristourne est considérée comme un transfert de l'État au secteur des entreprises. Par conséquent, l'augmentation des coûts de main-d'œuvre liée aux relèvements de salaire (réel) convenus dans le cadre de l'accord salarial 2009-10 sera enregistrée dans les comptes nationaux, mails la ristourne générale qui l'accompagne ne le sera pas, si bien que, dans les statistiques officielles, l'alourdissement des coûts salariaux apparaît plus important qu'il ne l'est en réalité. 
secteur des services, non exposé, où cette mesure n'a sans doute guère d'impact sur l'emploi. En revanche, ce dispositif a des chances d'améliorer la compétitivité extérieure dans certaines branches du secteur manufacturier, en particulier les industries chimique et automobile, qui ont un effet relativement puissant sur l'emploi dans d'autres secteurs. De plus, ces réductions ciblées peuvent aider à contrer les incitations à délocaliser la production qui résultent du niveau élevé des cotisations de sécurité sociale et des salaires minimums (van den Cruyce et Wera, 2007 ; Koskela et Poutvaara, 2008). Dans un monde caractérisé par l'intégration internationale des marchés, toutefois, la compétitivité-prix devient moins importante pour les pays développés du fait que leurs marchés d'exportation se maintiennent grâce à leur capacité d'élévation dans la chaîne de valeur ajoutée. Dans le court terme, cette mesure peut donc préserver des emplois, mais à un coût budgétaire très élevé. Dans le moyen terme, elle sera probablement plus efficace que les programmes de politique industrielle des années passées.

19. D'autres instruments permettant d'améliorer les perspectives d'emploi de certains groupes sur le marché du travail seraient peut-être plus efficaces par rapport à leur coût. Au cours des crises économiques, par exemple, les jeunes travailleurs sont touchés de façon disproportionnée, ce qui laisse penser que, dans le court terme, la réduction des cotisations patronales de sécurité sociale peut paraître indiquée pour stimuler la demande de main-d'œuvre pour ce groupe (graphique 8). Sur le moyen terme, il faudrait que cette mesure s'applique sans distinction d'âge afin d'éviter des effets de seuil et il faudrait renforcer les perspectives d'emploi de ce groupe au moyen d'autres instruments. Une mesure moins coûteuse du point de vue budgétaire - une considération importante compte tenu des problèmes de viabilité des finances publiques - serait, par exemple, d'avoir une augmentation plus progressive du salaire minimum pour les jeunes travailleurs, qui va actuellement de $70 \%$ à $82 \%$ à partir de l'âge de 18 ans, pour atteindre $100 \%$ à l'âge de 21 ans. D'après des résultats non concluants de travaux économétriques, cette mesure pourrait favoriser l'emploi de jeunes travailleurs (Bassanini et Duval, 2006). Le rapport coût-efficacité des nombreuses mesures pourrait sans doute être accru si l'on dédiait un seul instrument à chaque groupe. Les subventions salariales, par exemple, vont en principe à l'encontre des effets négatifs sur le marché du travail des salaires minimums élevés pratiqués dans certains secteurs. Ces rémunérations sont bien supérieures au taux légal, lequel, par rapport au salaire moyen, est plus élevé que dans presque tous les autres pays de l'OCDE (Immervoll et Pearson, 2009). Par ailleurs, le niveau relativement élevé des salaires minimums sectoriels indique que les partenaires sociaux ont la possibilité d'améliorer les perspectives d'emploi des travailleurs à bas salaire. Il en va de même pour les travailleurs généralement bien payés des industries chimique et automobile (pour lesquels le travail en dehors des horaires habituels est aussi généreusement rémunéré) et pour les séniors dont la rémunération est fonction de l'âge ou de l'ancienneté (les systèmes basés sur l'âge sont maintenant remplacés par des formules de rémunération fondées sur les compétences ou l'ancienneté, suite à une décision de la Cour de justice des Communautés européennes ; (OECD, 2009). Cependant, la possibilité pour les partenaires sociaux de parvenir à des accords salariaux préservant les emplois est limitée par le mécanisme d'indexation automatique des salaires. 
Graphique 8. Perspectives d'emploi pour les jeunes travailleurs dans la zone de l'OCDE 2007, jeunes de 15-24 ans

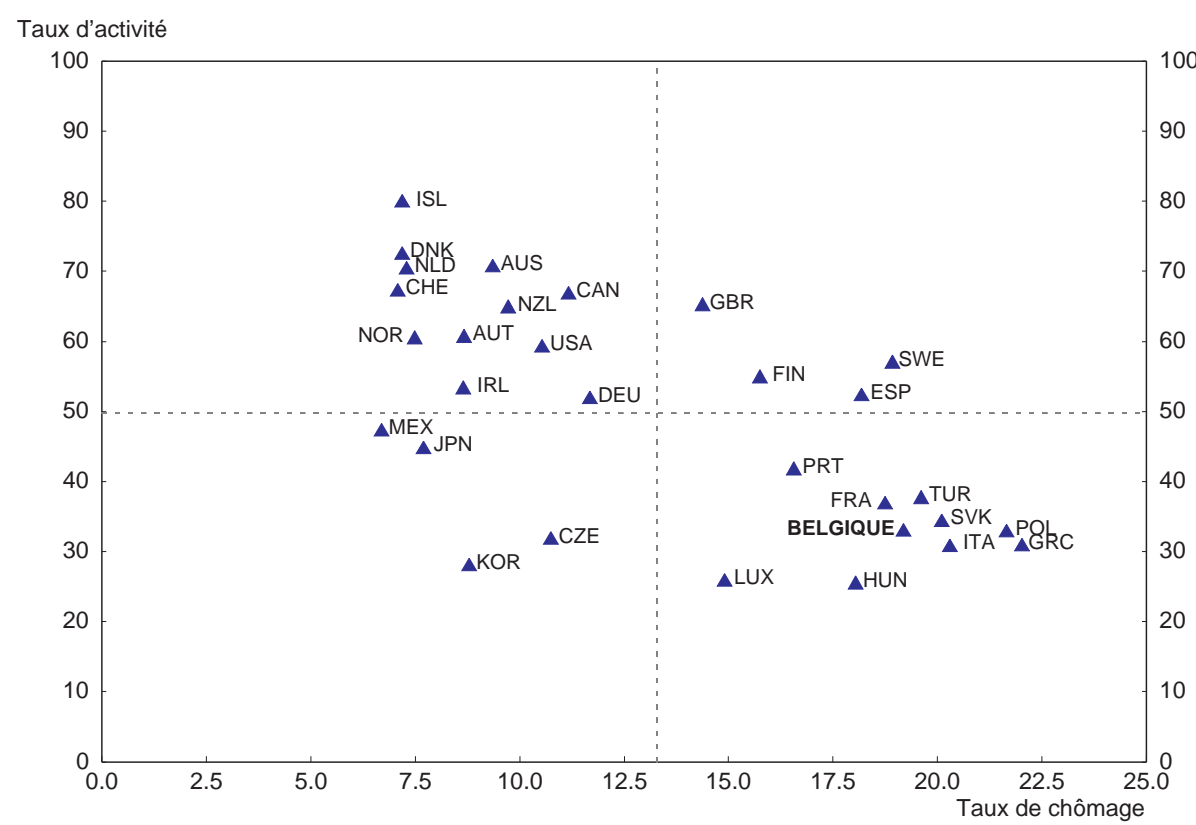

Source : OCDE, Base de données des Perspectives de l'emploi.

Malgré l'intervention des pouvoirs publics, les pièges du marché du travail restent de taille

20. Les taux effectifs d'imposition marginale sont élevés pour la plupart des travailleurs. A l'aide d'un modèle de micro-simulation, Decoster et al. (2008) ont montré que la majorité des hommes comme des femmes (indépendamment de leurs situation familiale) sont assujettis à des taux d'imposition marginaux de plus de $50 \%$. De surcroit, les taux marginaux effectifs sont généralement encore plus élevés du fait que plus de trois quart des femmes célibataires et environ la moitié des femmes mariées sont imposées à des taux de $60 \%$ ou plus. En particulier, le système de partage de la charge fiscale soumet celui des époux qui a un faible revenu (préférant généralement un travail à temps partiel) à des taux marginaux d'imposition sur le revenu supérieurs à ceux qui s'appliquent aux célibataires ayant un revenu similaire. L'élasticité de l'offre de travail des femmes étant relativement forte, cela parait avoir contribué au niveau relativement bas du nombre moyen d'heures ouvrées (graphique 9) (Jaumotte, 2003). En outre, les conjoints sans emploi sont couverts par le système de sécurité sociale par le biais des cotisations de celui qui travaille, ce qui donne des taux effectifs d'imposition marginale encore plus élevés. Afin d'augmenter le nombre d'heures ouvrées par les conjoints à faible revenu, le gouvernement devrait mettre en place intégralement le régime d'imposition séparée des conjoints, comme l'ont fait beaucoup d'autres pays de l'OCDE. Le nombre d'hommes assujettis à des taux effectifs similaires est encore plus grand, mais leur offre de travail est relativement peu élastique. 


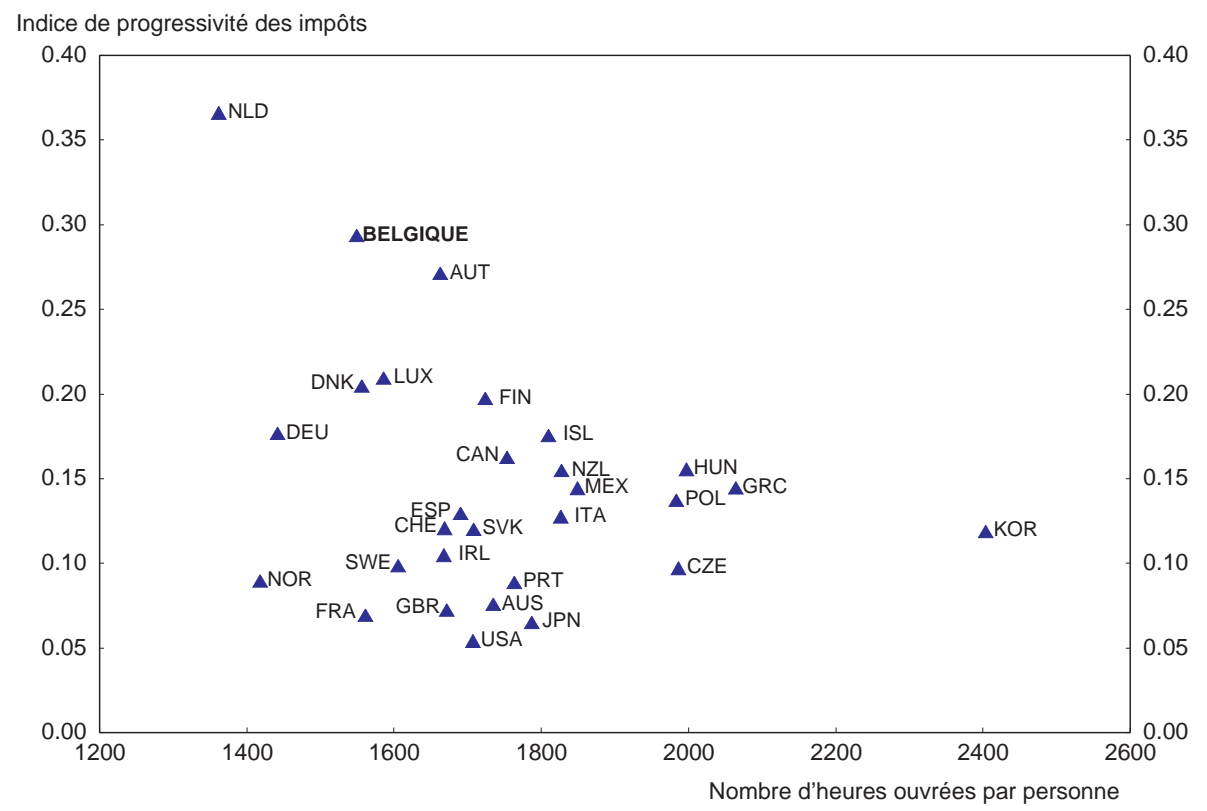

Source : OCDE (2009), Objectif croissance, et base de données de l'OCDE sur la productivité.

21. La réforme fiscale de 2002 et les mesures prises par la suite afin d'alléger les coûts de main-d'œuvre se sont traduites par une réduction des taux effectifs d'imposition marginale pour tous les types de ménages et tous les niveaux de revenu (OCDE, 2008). Parmi les nouvelles mesures mises en œuvre en 2008, on peut citer une augmentation des prestations liées à l'exercice d'un emploi, permettant aux demandeurs d'emploi qui acceptent un travail à temps partiel de recevoir des indemnités de chômage complémentaires, indépendamment de leur situation familiale et des prestations liées à l'exercice de l'emploi. De plus, un complément de salaire pour garde d'enfant a été mis en place et l'on envisage également un complément mobilité pour inciter plus fortement les chômeurs à étendre leur recherche d'emploi au-delà d'un rayon de $75 \mathrm{~km}$ autour de leur domicile et encourager les parents isolés à reprendre une activité. Néanmoins, les coins fiscaux belges sont parmi les plus élevés dans la zone de l'OCDE, ce qui, sur un marché du travail aussi rigide que celui de la Belgique, entrave l'adaptation sans heurts des salaires réels aux déséquilibres du marché du travail (graphique 10). De plus, la révision en 2007 de la Stratégie de l'OCDE pour l'emploi a montré qu'une réduction de 10 points du coin fiscal dans un pays moyen de l'OCDE majore, au fil du temps, le taux d'emploi de 3.7 points (OCDE, 2005).

22. Des coins fiscaux importants, conjugués à la suppression des diverses réductions de cotisations de sécurité sociale, conduisent au chômage, à l'inactivité et à des pièges de bas salaire pour les travailleurs faiblement rémunérés. A plus de $80 \%$, le taux marginal effectif d'imposition pour les chômeurs qui prennent un emploi à bas salaire reste parmi les plus élevés des pays européens de l'OCDE (tableau 4). Les trappes à inactivité, mesurées par le taux d'imposition effectif des bénéficiaires de prestations sociales qui prennent un emploi à bas salaire, ne sont pas si élevées, mais, à $70 \%$, elles demeurent dissuasives pour un ménage sans enfants comptant un seul apporteur de revenu. De plus, les travailleurs à bas salaire sont confrontés à des taux effectifs élevés d'imposition marginale lorsqu'ils montent l'échelle des salaires du fait que leurs prestations sont réduites. Selon la situation familiale, les trappes à bas salaires varient entre 45 et $58 \%$ pour les revenus les plus faibles, ce qui est relativement élevé parmi les pays européens de l'OCDE. 
Graphique 10. Le coin fiscal dans les différents pays en $2007^{1}$

En pourcentage des coûts de main-d'œuvre bruts, pour un célibataire sans enfants
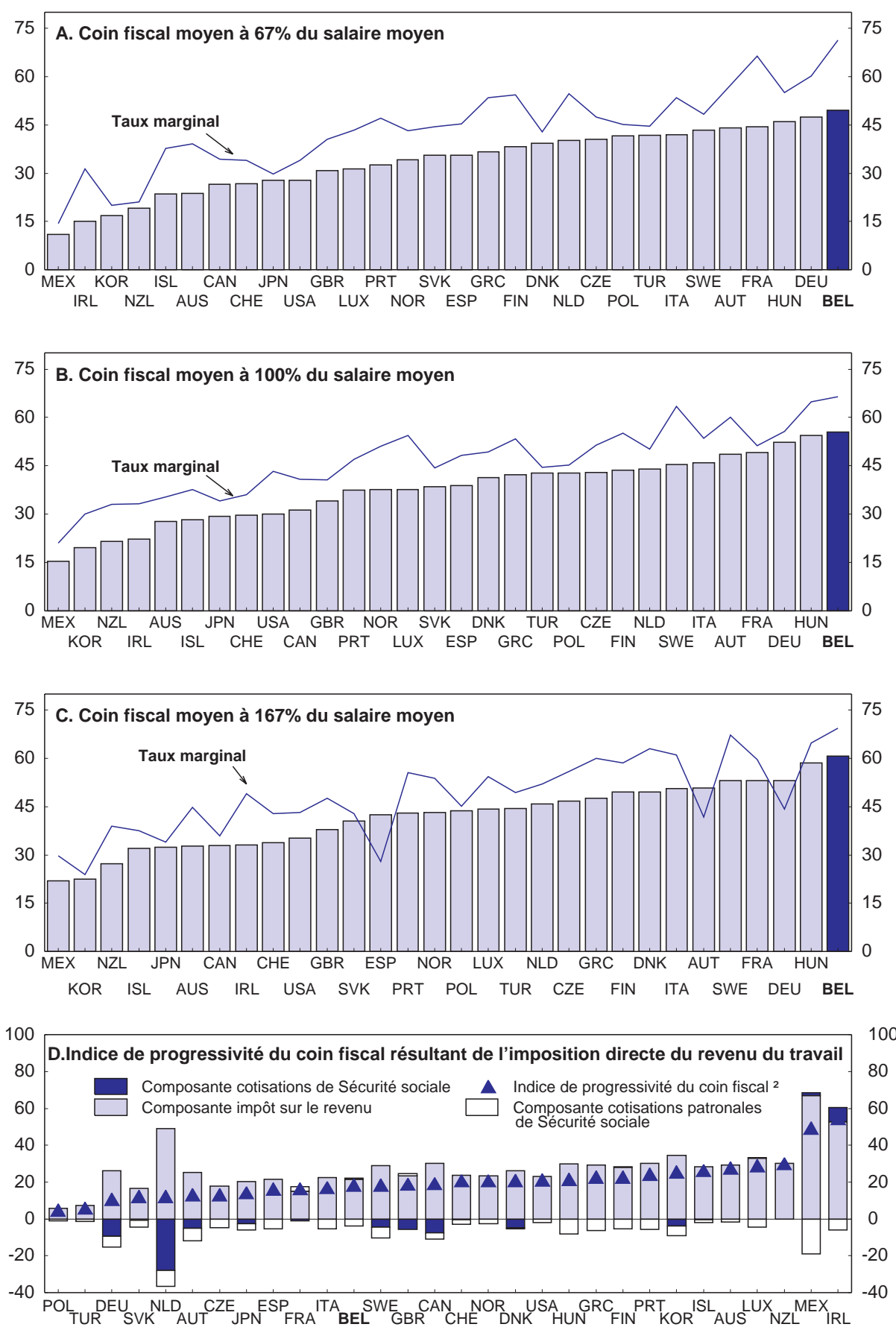

1. Le coin fiscal moyen est défini comme étant la part de l'impôt sur le revenu et de l'ensemble des cotisations de sécurité sociale, moins les prestations, dans les coûts de main-d'œuvre brut; les taux marginaux sont définis comme étant la part de l'augmentation de l'impôt et de l'ensemble des cotisations de sécurité sociale, moins les prestations, dans l'accroissement connexe des coûts de main-d'œuvre bruts.

2. L'indice de progressivité du coin fiscal est calculé suivant la formule (TW167 - TW67)/ TW167, où TW167 et TW67 représentent le coin fiscal pour les travailleurs rémunérés respectivement à $167 \%$ et $67 \%$ du salaire moyen.

Source : OCDE, Base de données fiscales. 
ECO/WKP(2009)82

Tableau 4. Les incitations financières au travail en Europe

\begin{tabular}{|c|c|c|c|c|c|c|c|c|c|c|c|c|}
\hline \multirow[b]{2}{*}{$\begin{array}{l}\% \text { du salaire } \\
\text { de l'ouvrier } \\
\text { moyen }\end{array}$} & Trapp & à chômage & Cé & bataire $^{1}$ & $\begin{array}{r}\text { c } \\
\text { con } \\
1 \text { apr } \\
\text { reve } \\
2 \epsilon\end{array}$ & $\begin{array}{l}\text { uple } \\
\text { portant } \\
\text { orteur de } \\
\text { lu, avec } \\
\text { lfants }^{2}\end{array}$ & Cél & sateur de tr & $\begin{array}{r}\text { Coupl } \\
1 \text { ap } \\
\text { rev } \\
2\end{array}$ & $\begin{array}{l}\text { laires } \\
\text { omportant } \\
\text { rteur de } \\
\text {, avec } \\
\text { fants }\end{array}$ & Taux de & $\begin{array}{l}\text { nplacement } \\
\text { et }\end{array}$ \\
\hline & 2007 & $\begin{array}{l}\text { Variation } \\
2001-07\end{array}$ & 2007 & $\begin{array}{l}\text { Variation } \\
2001-07\end{array}$ & 2007 & $\begin{array}{l}\text { Variation } \\
2001-07\end{array}$ & 2007 & $\begin{array}{l}\text { Variation } \\
2001-07\end{array}$ & 2007 & $\begin{array}{l}\text { Variation } \\
2001-07\end{array}$ & 2007 & $\begin{array}{l}\text { Variation } \\
2001-07\end{array}$ \\
\hline Autriche & 68 & 0.6 & 64 & -2.8 & 82 & -6.9 & 38 & 3.1 & 65 & -17.2 & 55 & -12.7 \\
\hline Belgique & 83 & -2.3 & 66 & 0.1 & 63 & -3.5 & 59 & 2.3 & 45 & 2.7 & 74 & -8.9 \\
\hline Rép. tchèque & 83 & -2.3 & 66 & 0.1 & 63 & -3.5 & 59 & 2.3 & 45 & 2.7 & 74 & -8.9 \\
\hline Danemark & 90 & -1.7 & 88 & -1.9 & 84 & -11.4 & 56 & -3.3 & 72 & -21.5 & 85 & -2.0 \\
\hline Estonie & 82 & 1.7 & 44 & 1.6 & 52 & -5.8 & 26 & 1.2 & 10 & -18.0 & 78 & 2.4 \\
\hline Finlande & 75 & -5.4 & 73 & -4.3 & 92 & -5.7 & 62 & 6.7 & 100 & 4.0 & 67 & -7.0 \\
\hline France & 81 & 0.2 & 61 & -2.7 & 80 & -0.1 & 41 & -2.6 & 63 & -5.9 & 75 & -8.4 \\
\hline Allemagne & 75 & 0.7 & 68 & 1.6 & 81 & 5.2 & 51 & -1.4 & 82 & 1.7 & 61 & -20.9 \\
\hline Grèce & 59 & 2.1 & 17 & 0.3 & 16 & 0.1 & 19 & 0.4 & 16 & 0.1 & 50 & -13.3 \\
\hline Hongrie & 77 & 5.9 & 46 & -4.5 & 59 & 1.6 & 37 & -4.6 & 37 & 9.1 & 73 & 7.9 \\
\hline Irlande & 76 & 3.7 & 76 & 3.7 & 88 & 1.2 & 52 & 7.9 & 78 & -3.8 & 74 & 5.0 \\
\hline Italie & 72 & 12.5 & 22 & 2.2 & -8 & -0.4 & 34 & 4.2 & 11 & -0.6 & 64 & 14.5 \\
\hline Luxembourg & 88 & 0.0 & 68 & 0.3 & 89 & 0.4 & 51 & 7.7 & 110 & 14.6 & 85 & 0.3 \\
\hline Pays-Bas & 86 & 7.0 & 85 & 4.5 & 88 & 1.0 & 59 & -2.6 & 78 & -3.2 & 80 & 0.4 \\
\hline Pologne & 79 & -1.5 & 56 & 4.1 & 63 & -3.8 & 38 & 0.4 & 72 & -4.0 & 70 & 2.5 \\
\hline Portugal & 82 & 0.5 & 37 & 0.4 & 57 & -0.1 & 22 & 1.2 & 56 & -1.5 & 78 & -7.9 \\
\hline Suède & 82 & -5.2 & 73 & -6.6 & 90 & -7.8 & 47 & -12.9 & 80 & -15.8 & 76 & -5.8 \\
\hline Royaume-Uni & 68 & -0.3 & 68 & -0.3 & 80 & 4.0 & 57 & -0.4 & 85 & 7.2 & 58 & -5.5 \\
\hline
\end{tabular}

1. $67 \%$ du revenu moyen.

1. $67 \%$ du revenu moyen.

$33-67 \%$ du revenu moyen.

Source : Services de la Commission européenne, sur la base du projet réalisé conjointement par la CE et l'OCDE METRS. 
23. Une réforme de la fiscalité du travail doit englober l'impôt sur le revenu des personnes physiques et les cotisations de sécurité sociale. En tout état de cause, avec les nombreuses exonérations et les allégements ciblés, la plupart des salariés considèrent sans doute déjà les cotisations de sécurité sociale comme un autre impôt plutôt que comme des prestations différées. Élargir la base des cotisations de sécurité sociale signifie que celles-ci doivent être fonction du revenu. Il faut donc supprimer les exonérations pour les travailleurs indépendants et les retraités ${ }^{7}$. Par ailleurs, afin d'accroître l'efficacité des subventions salariales par rapport à leur coût, il faudrait les limiter aux groupes ayant de médiocres perspectives sur le marché du travail, c'est-à-dire les travailleurs à bas salaire. Certains allégements ciblés à caractère temporaire pourraient être maintenus pour les jeunes travailleurs non qualifiés, et complétés par un accès plus progressif aux salaires minimums. Les partenaires sociaux devraient assumer la responsabilité des perspectives d'emploi des autres groupes au lieu de s'en remettre aux finances publiques pour atteindre cet objectif. Enfin, pour compléter la réforme, il faudrait aussi supprimer les pics des taux effectifs d'imposition marginale afin de résorber les trappes à inactivité qui susbsistent sur le marché du travail.

\section{Le système d'impôt sur les bénéfices des sociétés est devenu plus neutre vis-à-vis des divers types de financement}

24. Les impôts sur les bénéfices des sociétés influent sur la croissance par leurs effets sur le taux de rendement après impôt des investissements qui servent de base pour la création d'emplois, ainsi que sur la productivité, du fait de l'adoption de nouveaux produits et technologies. Ce sont ces considérations qui ont motivé les réductions des taux nominaux et effectifs de l'impôt sur les sociétés dans le cadre de la réforme fiscale de 2002, même si ces derniers demeurent relativement élevés (graphique 11). Une réforme supplémentaire, en 2005, a rendu la fiscalité des sociétés plus neutre vis-à-vis des divers types de financement, grâce à la mise en place de la « déduction pour capital à risque », supprimant en grande partie les incitations au financement par l'emprunt qui existent dans beaucoup d'autres pays de l'OCDE. D'après les premières estimations, la réforme de 2002 a été à peu près neutre sur le plan budgétaire, comme prévu initialement, en dépit de fortes variations suivant la conjoncture économique (graphique 12) (OCDE, 2004).

25. L'origine de la réforme de 2005 a été une décision de la Commission européenne, qui a estimé que le régime précédent, dans lequel il existait des centres de coordination pour les entreprises multinationales, n'était pas compatible avec les règles de l'UE régissant les aides publiques (encadré 3) (Burggraeve et al., 2008). La déduction pour capital à risque (appelée "régimes des intérêts notionels ») est en vigueur depuis l'exercice fiscal 2007 et elle permet aux entreprises de déduire de leur base imposable un montant notionel d'intérêts (calculé sur la base du taux des obligations émisses par l'État à 10 ans deux ans avant l'année d'imposition) sur leurs fonds propres (ajustés) ${ }^{8}$. Le système est unique au niveau international, même si certains pays ont eu dans le passé des dispositifs de ce type (Brésil et Nouvelle-Zélande) ou si l'on en trouve certains éléments dans leur code des impôts (Autriche, Italie, Irlande, Luxembourg et Suisse). Indépendamment de l'objectif de neutralité, la réforme a visé aussi à offrir aux entreprises internationales qui utilisaient les centres de coordination un autre moyen attrayant d'assurer à la Belgique une position assez singulière dans la zone de l'OCDE en tant que bénéficiaire net d'IDE une source importante de transfert de technologie (OCDE, 2007a). Une procédure pour infraction a été

7. Pour des raisons de redistribution des revenus, la suppression des exonérations pour les retraités pourrait nécessiter une augmentation de leurs pensions.

8. Pour les PME, le taux autorisé est majoré de 0.5 point de pourcentage. Un plafond supplémentaire s'applique aux relèvements du taux autorisé du fait que ce taux ne peut pas varier de plus de 1 point d'une année à l'autre. Par ailleurs, les entreprises qui ont des bénéfices insuffisants pour bénéficier pleinement de la déduction pour capital à risque peuvent reporter la déduction pendant sept ans, créant ainsi une réserve d'impôt. 
ouverte à la Commission européenne au début de 2009 parce que la déduction au titre des intérêts théoriques ne s'applique pas aux entreprises belges investissant à l'étranger.

\section{Graphique 11. Taux d'imposition sur les sociétés : comparaison internationale}
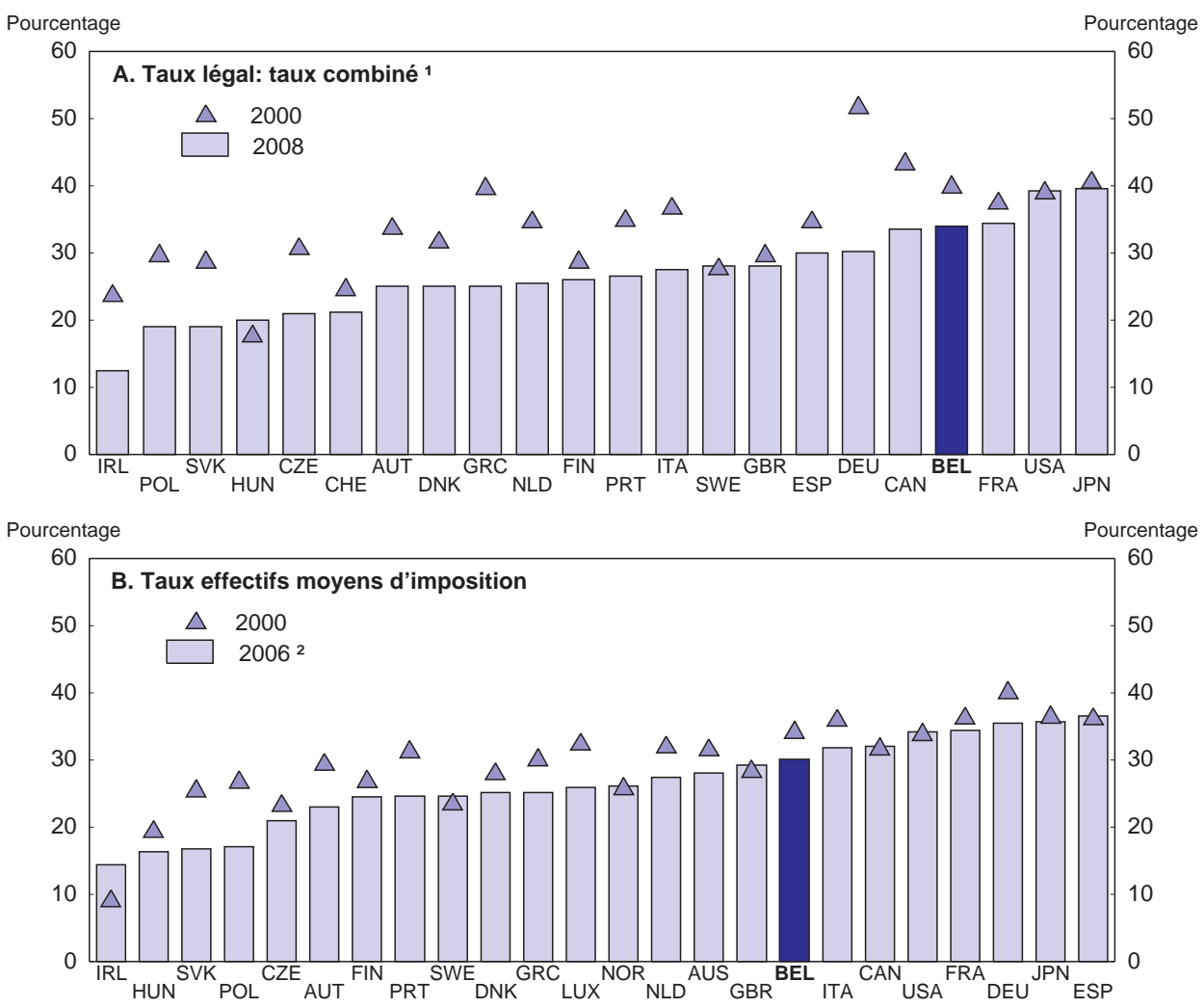

1. Taux d'imposition (légal) de base combiné prélevé sur les bénéfices des sociétés aux niveaux national et infranational. Les agrégats sont des moyennes non pondérées et l'UE 10 couvre les nouveaux États membres de l'UE.

2. Les données se rapportent à 2005 pour l'Australie, le Canada, le Japon, la Norvège et les États-Unis.

Source : OCDE (2007), «Effective tax rates in an enlarged European Union », Working Party No. 2 Tax Policy Analysis and Tax Statistics, préparé par la Commission européenne à partir d'enquête préparé par Zentrum für Europäische Wirtschaftsforchung et Statistiques financière internationales, OCDE (2007) base de données fiscales, www.oecd.org/ctp/taxdatabase et Commission européenne (2006) Structures of the Taxation Systems in the European Union. 
Graphique 12. Taux et recettes de l'impôt sur les sociétés

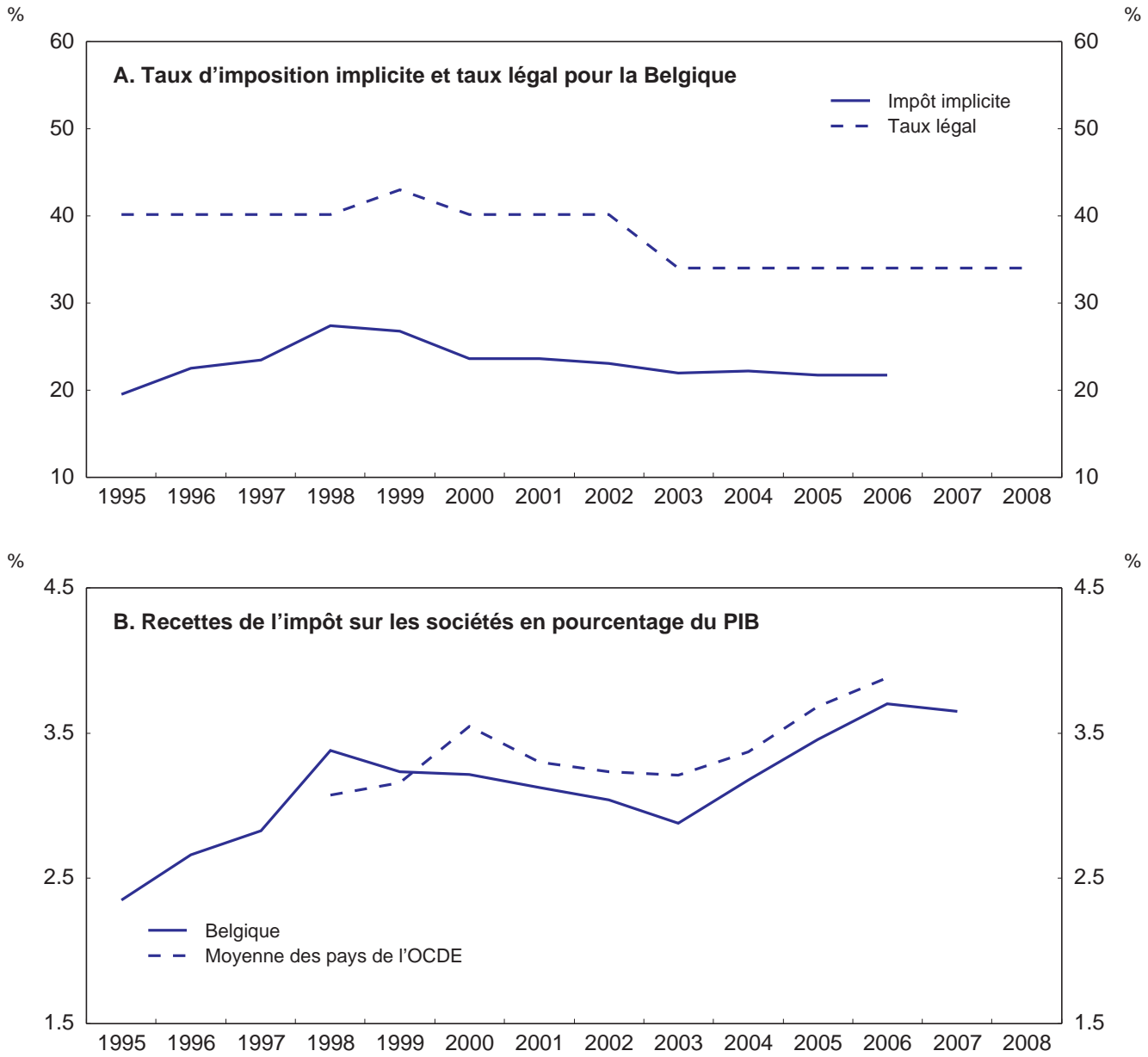

Source : Eurostat $(2008,2007)$, Taxation trends in the European Union, et OCDE, base de données fiscales.

\section{Encadré 3. Les centres de coordination}

Les centres de coordination sont des entreprises qui appartiennent à des groupes multinationaux et qui ont pour seule fin de fournir des services financiers, de gestion de la trésorerie, de comptabilité, de conseil et autres aux autres entreprises du même groupe. Ils bénéficient de règles fiscales spéciales avec un régime particulièrement avantageux pour les opérations interentreprises. Les dépenses fiscales à ce titre s'élevaient à un peu moins de 1.9 milliard EUR pour l'exercice fiscal 2004. Les centres de coordination, dans ce contexte, sont définis comme des entreprises qui gèrent les flux financiers d'un groupe multinational ayant des activités dans au moins quatre pays. Pour pouvoir bénéficier des règles fiscales spéciales, les entreprises doivent avoir un chiffre d'affaires consolidé d'au moins 240 millions EUR et un capital consolidé d'au moins 24 millions EUR. Une condition supplémentaire est que les participations étrangères doivent atteindre au moins 12 millions EUR ou $20 \%$ des capitaux étrangers du groupe. Par ailleurs, les centres de coordination doivent employer au moins 10 travailleurs à temps plein au bout de deux années de fonctionnement.

La Commission européenne ayant jugé le régime fiscal spécial des centres de coordination incompatible avec les règles relatives aux aides publiques, le gouvernement belge a décidé de le supprimer progressivement jusqu'à la fin de 2010. Lorsque les centres de coordination perdent ou abandonnent leur agrément, ils tombent sous le coup des règles ordinaires d'imposition des sociétés et peuvent par conséquent bénéficier de la déduction pour capital à risque. Cette dernière semble leur convenir tout particulièrement puisqu'ils se caractérisent par des niveaux élevés de fonds propres (un total de quelque 170 milliards EUR en 2006), sur lequel ils obtiennent un rendement relativement faible 
étant donné que le gros de leurs recettes provient généralement des intérêts perçus sur les prêts qu'ils accordent aux autres entreprises du groupe.

Par suite de l'entrée en vigueur des nouvelles règles, le nombre de centres de coordination actifs a diminué de 226 en 2004 à 74 au printemps de 2008. Certains d'entre eux ont choisi de transférer leurs activités vers d'autres centres financiers, la Suisse en particulier. De plus, un certain nombre de centres de coordination ont choisi de recourir à la déduction pour capital à risque. Par ailleurs, leur capital net a fortement augmenté, par suite de légères sorties initiales de capitaux, suivies d'entrées plus importantes, même si l'on ne pourra évaluer l'effet final qu'une fois que tous les centres de coordinations auront été fermés. On pourrait conclure provisoirement que bon nombre de ces centres considèrent la déduction pour capital à risque comme une solution de remplacement acceptable.

26. Une première analyse révèle que, alors que l'ancien système favorisait le financement par l'emprunt pour tous les types d'investisseurs, le nouveau régime est plus neutre (Gérard, 2009). Aujourd'hui, le mode de financement préféré des investisseurs individuels est l'utilisation des bénéfices non distribués, tandis que pour les sociétés holdings le système est pratiquement neutre entre le financement à l'aide de capitaux frais et le financement à l'aide des bénéfices non distribués. Cela a sans doute contribué à une nette augmentation des fonds propres (près de 250 milliards EUR pour la période 2006-07), dont la moitié en provenance de l'étranger. Dans le même temps, la part des fonds propres dans le secteur non financier s'est accrue, du fait notamment du développement des participations croisées, mais cela pourrait néanmoins indiquer une amélioration de la solvabilité, du fait en particulier que les entreprises ont semblé en même temps réduire leurs emprunts. Si l'on utilise le taux d'intérêt exempt de risque de la dette publique pour calculer le taux théorique, ce dernier est plus bas que le taux d'intérêt sur le financement par l'emprunt, ce qui signifie que, du point de vue des entreprises, il reste assez avantageux de recourir à l'emprunt. Achever la réforme visant à rendre le système d'imposition des sociétés parfaitement neutre vis-à-vis des divers types de financement, par exemple en utilisant un taux théorique qui correspond davantage au coût effectif du financement, pourrait améliorer la croissance de la productivité totale des facteurs (PTF) car les formes de financement choisies seraient indépendantes du traitement fiscal, ce qui pourrait, par exemple, améliorer les conditions de financement pour les branches d'activité fondées sur le savoir qui utilisent généralement leurs fonds propres pour financer leurs investissements incorporels (Johannson et al., 2008).

27. Plusieurs mesures ont été prises afin de stimuler la croissance et l'innovation dans les jeunes entreprises de pointe, qui bénéficient de taux d'imposition réduits et d'une déduction fiscale spéciale pour les jeunes PME innovantes - définies comme étant des entreprises comptant moins de 50 salariés, créées il y a moins de dix ans et ayant un chiffre d'affaires annuel inférieur à 7.3 millions EUR, dont au moins $15 \%$ servent à financer la R-D - en plus des subventions salariales générales et des déductions fiscales au titre du personnel de R-D (Johannson et al., 2008 ; van Cauter et al., 2004). Par ailleurs, il existe au niveau régional d'importantes subventions supplémentaires en faveur de la R-D, en particulier pour les PME. Au plan général, les créditsd' impôt pour des investissements en R-D sont plus efficaces pour encourager les activités d'innovation que les subventions directes, mais il faut du temps pour en profiter et l'effet est limité. De plus, des dépenses de R-D plus élevées n'ont qu'un faible impact sur les PTF globale (Jaumotte et Pain, 2005a et b). Cependant, ces mesures sont probablement moins efficaces lorsqu'elles visent les PME en raison de leur capacité de recherche limitée. Cela met en question le rapport coût-efficacité de ces dispositifs. De fait, on stimule plus efficacement la R-D par le biais de marchés de produits et de marchés du travail flexibles (OECD, 2009). Les taux réduits d'impôt sur les sociétés dont bénéficient les PME sont normalement justifiés par les défaillances des marchés financiers ou de produits, mais comme les nouvelles petites entreprises paient rarement l'impôt sur les sociétés étant donné que beaucoup d'entre elles sont des start-ups peu rentables, la mesure n'est pas efficace pour pallier ces défaillances des marchés. En revanche, des taux réduits peuvent dissuader les petites entreprises de se développer au-delà d'une taille inférieure à leur échelle de production optimale. Etant donné leur faible rendement dans le secteur des petites entreprises et leurs effets négatifs potentiels pour la croissance, les taux réduits d'impôt sur les sociétés pourraient donc tout simplement être supprimés. D'autre part, il conviendrait d'abaisser le niveau 
relativement élevé du taux ordinaire de l'impôt sur les sociétés afin d'accroître le rendement après impôt du capital investi et de stimuler ainsi les investissements privés et la croissance de la PTF (Johannson et al., 2008). Cela est particulièrement important pour les entreprises en phase de rattrapage (par rapport à celles qui affichent les meilleurs niveaux de productivité) du fait que ces entreprises financent probablement leurs activités de R-D à l'aide de leurs bénéfices non distribués. Ces taux doivent être réduits dans une proportion reflétant la nécessité de maintenir un environnement favorable pour attirer l'IDE dans l'avenir.

\section{Le traitement fiscal de l'épargne varie considérablement selon les instruments}

28. Il existe de très grandes différences dans le traitement fiscal des instruments d'épargne (graphique 13). L'investissement dans la résidence principale et les placements relatifs au troisième pilier de retraite sont relativement plus favorisés sur le plan fiscal que l'épargne investie dans d'autres actifs financiers comme les dépôts, les obligations d'État ou les actions. La préférence donnée par le régime fiscal à certains instruments a pour but de stimuler l'épargne privée. Comme il était indiqué dans l'Étude précédente, cependant, ces mesures ne font pas monter le niveau global de l'épargne privée, malgré un coût parfois substantiel pour le budget, et elles n'ont donc guère d'effet sur la croissance. D'autre part, elles tendent à orienter l'épargne vers des instruments qui n'ont pas nécessairement le rendement avant impôt le plus élevé, ce qui entrave l'allocation du capital et la croissance de la productivité.

\section{Graphique 13. L'imposition effective des instruments d'épargne varie considérablement}

Taux effectifs d'imposition, 2001-20041

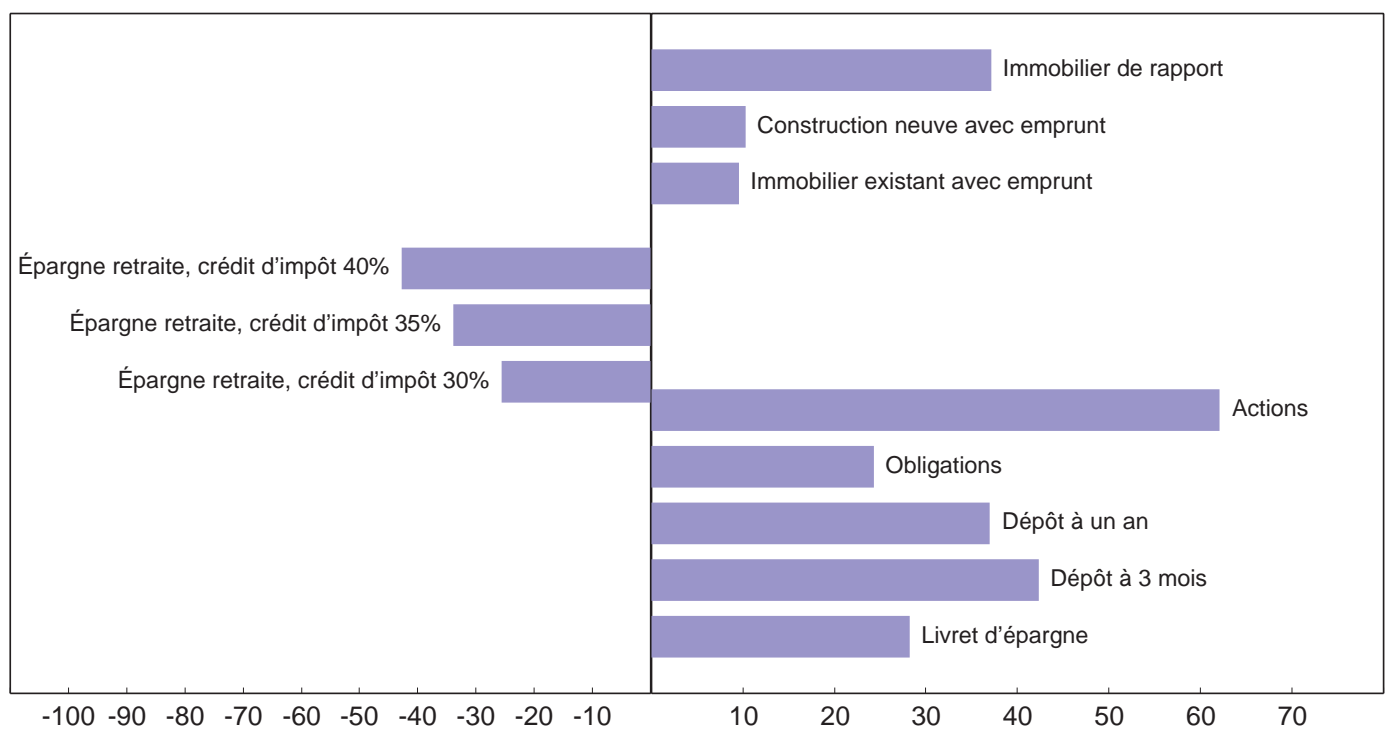

1. Les taux effectifs d'imposition sont égaux à la différence entre les taux de rendement bruts et nets rapportée au taux de rendement brut réel (corrigé de l'inflation). L'imposition effective varie en fonction du taux de rendement net car les différents types d'instrument ne sont pas soumis au même régime. Les actions sont aujourd'hui plus faiblement imposées que ce qui est indiqué sur le graphique du fait de la déductibilité des intérêts notionels.

Source: Valenduc, C. (2003), "Effective taxation of households saving in Belgium", document présenté au 59ème congrès de I'International Institute for Public Finance, "Public Finance and Financial markets".

\section{La résidence principale est peu imposée}

29. Le produit des taxes sur la propriété immobilière est moins important que dans la plupart des autres pays de l'OCDE (graphique 14). Les dispositions du système d'imposition des personnes physiques 
concernant la résidence principale comportent deux grands éléments : la déductibilité des paiements hypothécaires et un impôt sur les loyers imputés. Depuis 2005, la déduction est octroyée au taux marginal d'imposition, soit le plus élevé, et elle s'applique plus largement que dans d'autres pays puisqu'elle couvre tous les paiements (c'est-à-dire intérêts, capital et primes d'assurance-vie) et qu'il existe un généreux plafond de 1990 EUR par conjoint, majoré de 660 EUR les 10 premières années, sur le montant maximum exempté chaque année (OCDE, 2007b). Cet avantage fiscal est en principe compensé par un impôt sur les loyers imputés. Cependant, comme les estimations utilisées pour le calcul de cet impôt reposent sur la valeur des biens en 1975, indexée depuis 1991 sur l'évolution de l'indice des prix à la consommation, elles sont (en moyenne) inférieures à $50 \%$ de la valeur du marché. La loi prévoit normalement une réévaluation tous les 10 ans, mais le ministère fédéral des Finances n'est guère incité à s'acquitter de cette coûteuse responsabilité dans la mesure où le surcroît de recettes fiscales qui doit en résulter revient aux régions et, plus encore, aux communes (moyennant un prélèvement proportionnel sur la valeur fiscale du bien). De plus, depuis le remaniement du Code des impôts en 2005, les loyers imputés ne sont plus imposables (Valenduc, 2008).

\section{Graphique 14. Taxes sur la propriété immobilière}

En pourcentage du PIB, $2007^{1}$

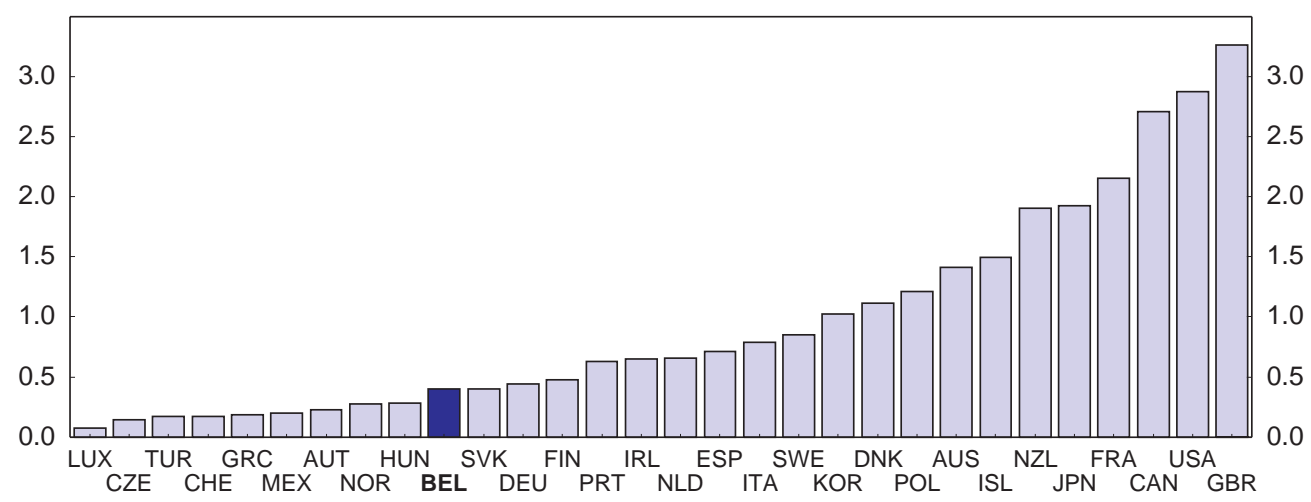

1. 2006 pour l'Australie, la Belgique, la Grèce, le Mexique, les Pays-Bas et la Pologne.

Source : OCDE, Base de données Statistiques des recettes publiques.

30. Les gagnants du système sont les propriétaires de logements donnés en location étant donné l'écart de plus en plus grand entre la valeur locative de leur bien sur le marché et celle du loyer imputé, tandis que les perdants sont ceux qui vivent dans certains quartiers naguère très cotés des grandes villes, à Bruxelles par exemple, et dont l'imposition n'a pas varié alors que la valeur relative de leur logement a baissé. De plus, le traitement fiscal préférentiel du logement constitue un obstacle à la croissance dans la mesure où il en résultera à terme une hausse des prix de l'immobilier qui, conjuguée au niveau élevé des frais de transaction comparativement aux autres pays (voir la précédente Étude), aura pour effet de réduire la mobilité de la main-d'œuvre et par conséquent de nuire à l'allocation efficiente des ressources sur le marché du travail. Pour stimuler l'activité, renforcer les mesures de redistribution des revenus et faire une plus large place aux impôts qui faussent le moins la croissance, il conviendrait d'accroître la fiscalité du logement. La principale mesure à envisager dans cette optique consiste à alourdir l'imposition effective des loyers imputés grâce à une évaluation plus réaliste de la valeur des biens immobiliers et à l'extension de la mesure à toutes les propriétés. Pour obtenir des estimations plus proches de la réalité du marché, on pourrait par exemple confier aux régions la responsabilité de cette évaluation. D'autre part, la déduction d'impôt consentie sur les remboursements hypothécaires devrait être limitée aux intérêts et exclure les remboursements en capital. Cette réforme pourrait produire des recettes supplémentaires de l'ordre 
de $0.2 \%$ du PIB ${ }^{8}$. Néanmoins, comme la part des recettes fiscales immobilières resterait quand même plus faible en Belgique que dans les autres pays, il faudrait aussi relever le taux de prélèvement pour permettre une réduction de la fiscalité dans d'autres domaines. Si l'impôt sur les loyers imputés s'avérait difficile à réformer, on pourrait alors envisager une réduction drastique des possibilités de déduction des paiements hypothécaires.

31. Un certain nombre d'instruments financiers d'épargne financière bénéficient également d'un régime fiscal préférentiel, par exemple les livrets d'épargne réglementés, les contrats d'assurance-vie et les produits de retraite du deuxième et du troisième pilier. Les dépenses fiscales qui en découlent pour l'État sont sans doute justifiées car elles stimulent l'épargne globale et par conséquent la croissance à long terme. Les livrets d'épargne défiscalisés sont particulièrement populaires (on en compte quelque $70 \%$ de plus que d'habitants, pour un encours total représentant plus de $50 \%$ du PIB). Ils sont totalement exonérés d'impôt sur les intérêts perçus jusqu'à concurrence de 1730 EUR (en 2009) et fonctionnent en fait pratiquement comme des comptes courants ordinaires puisque l'épargnant peut dans bien des cas retirer ses fonds à tout moment (OCDE, 2007c). Au-dessus du montant exonéré, les intérêts sont soumis à un précompte de $15 \%$. Les versements effectués sur les contrats d'assurance-vie bénéficiant d'avantages fiscaux et les contributions aux plans de retraite du troisième pilier sont exonérés d'impôt (dans la limite de 1950 EUR et 810 EUR respectivement en 2007). Les contributions aux plans de retraite du deuxième pilier sont également exonérées lorsque les prestations sont plafonnées à $80 \%$ du dernier revenu professionnel. En outre, dans le cas de l'assurance-vie, le capital versé à l'échéance du contrat est soumis à un prélèvement de $10 \%$ au titre de l'impôt des personnes physiques (un taux de $16.5 \%$ s'applique aux contributions versées avant 1992), augmenté d'une contribution de $3.55 \%$ au système de sécurité sociale pour l'assurance médicale 9 . Par comparaison, l'imposition des dividendes est beaucoup plus élevée, puisqu'à l'impôt des personnes physiques ( $25 \%$ ou $15 \%$ dans certains cas) s'ajoute l'impôt des sociétés, ce qui donne un taux légal de prélèvement global de plus de $40 \%$, soit un peu plus que la moyenne OCDE (graphique 15). Cette fiscalité plus lourde peut être contournée car en l'absence de taxation des gains en capital, le financement d'investissements sur les bénéfices non distribués peut faire monter la valeur des actions (exemptée d'impôt). Cependant, les investissements réalisés pour des raisons fiscales n'étant pas nécessairement ceux qui offrent le meilleur rendement possible, il peut en résulter une mauvaise allocation du capital et une croissance de la productivité plus faible qu'elle ne le serait autrement. De plus, il se peut aussi que le système réduise le volume des financements disponibles pour les nouvelles entreprises, au point de constituer un désavantage compétitif si celles-ci sont obligées d'émettre des actions pour se procurer des capitaux (les investisseurs exigeant un rendement plus élevé pour les émissions nouvelles).

32. Les dépenses fiscales correspondantes représentent à peu près $0.25 \% \mathrm{du} \mathrm{PIB}$, soit un niveau plus élevé que dans la plupart des autres pays membres de l'OCDE (OCDE, 2007b). Dans la mesure où les fonds ne sont pas immobilisés, le livret d'épargne ne se distingue pratiquement pas d'un compte courant ordinaire, ce qui jette un doute sur la capacité de cet instrument à renforcer les incitations à l'épargne. De plus, les épargnants ne profitent pas entièrement des avantages de l'exonération fiscale car le taux effectif net d'imposition est plus élevé sur les dépôts imposables que sur les livrets d'épargne (Valenduc, 2003). S'agissant des contrats d'assurance-vie, les données internationales indiquent que les produits à régime fiscal préférentiel n'ont un effet positif sur le niveau global de l'épargne que s'ils sont utilisés par les ménages à faible revenu. Or, comme leur taux d'utilisation augmente avec le revenu, l'effet qu'ils exercent

8. On pourrait aussi ajuster le taux du précompte immobilier, un impôt foncier prélevé par les régions et majoré par les communes, qui a eu tendance à dériver à la hausse pour compenser l'indexation partielle des prix des logements.

9. En cas de retrait des fonds avant la fin du contrat, l'assureur doit payer une taxe de $33 \%$ sur la valeur de rachat. De son côté, le contribuable a droit à un crédit d'impôt équivalant au taux d'imposition moyen des primes versées sur une année, avec un maximum de $15 \%$ sur les premiers 1500 EUR de revenu plus $6 \%$ sur le solde dans la limite d'un plafond de 1800 EUR (2003). 


\section{Graphique 15. Taux légal d'imposition globale des dividendes}

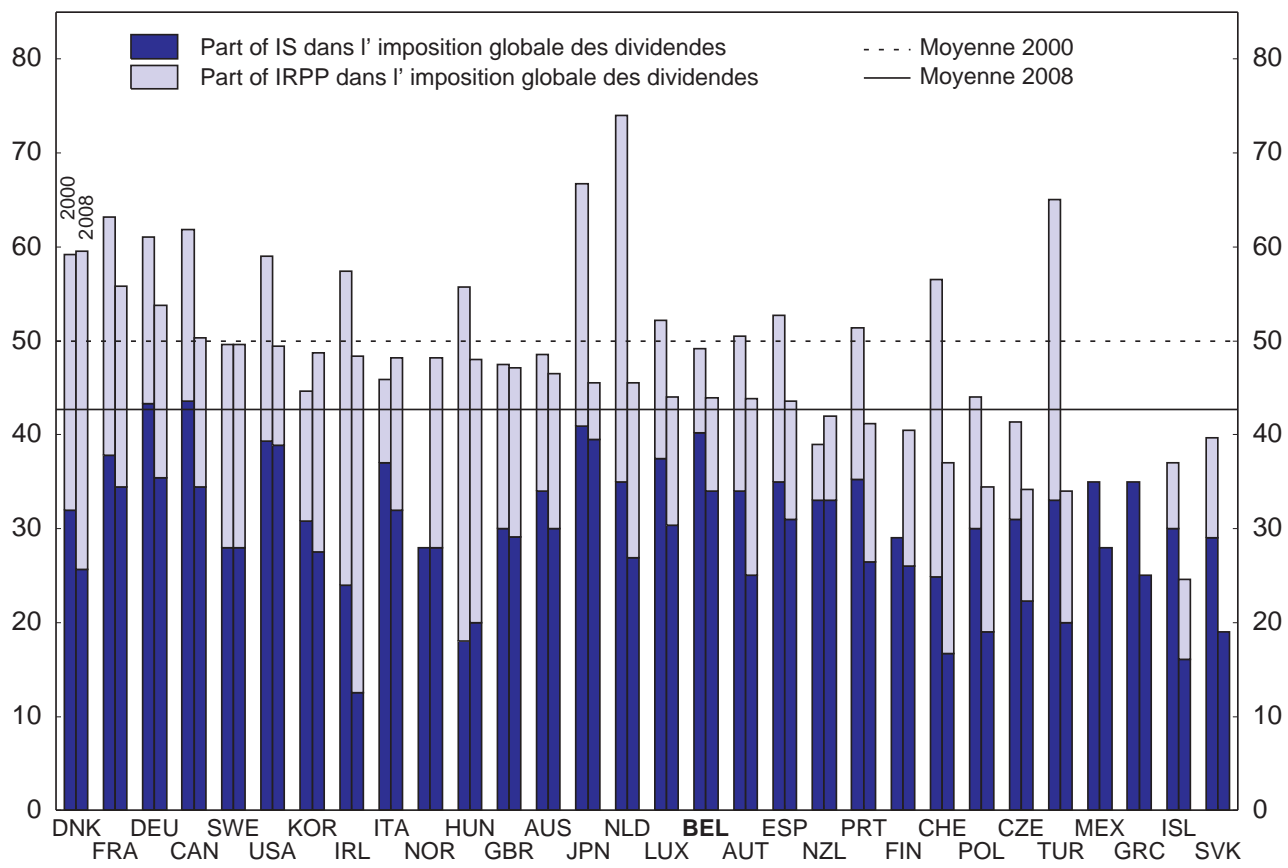

1. Pour les actions et parts émises avant le 1er janvier 1994, l'impôt sur le revenu des personnes physiques (perçu à la source) s'applique au taux de $25 \%$. Cette retenue constitue l'impôt définitif de l'actionnaire s'il en décide ainsi. Plus le dividende avant impôt est faible, plus le taux effectif d'imposition est bas du fait de la déduction des intérêts notionels: le taux effectif d'imposition des sociétés ne représente que la moitié du taux nominal légal lorsque le rendement des capitaux propres avant impôt est égal au double du taux d'intérêt théorique (4.307 \% en 2008).

Source : OCDE, Base de données fiscales.

sur l'épargne est tout au plus modeste et sans doute pas suffisant pour justifier le niveau élevé des dépenses fiscales correspondantes. En résumé, les instruments d'épargne à régime fiscal préférentiel ne semblent guère avoir d'effet sur l'épargne, alors qu'ils coûtent cher au budget. Par conséquent, en vue de stimuler la croissance économique, il faudrait éliminer ces avantages fiscaux pour élargir la base d'imposition, uniformiser la taxation des instruments d'épargne et la compléter lorsqu'il y a lieu par une taxe sur les gains en capital. Cette réforme devrait être appliquée sur une période suffisamment longue afin de ne pas ajouter à l'instabilité financière actuelle.

33. A cet égard, l'adoption officielle par la Belgique de la norme de l'OCDE pour l'échange de renseignements en matière fiscale et la décision qu'elle a prise en mars 2009 de lever sa réserve concernant l'article 26 du Modèle OCDE de convention sur le revenu et le capital méritent d'être saluées. La Belgique avait déjà signé une première convention fiscale sur le revenu conforme à la norme de l'article 26 en 2006 et indiqué qu'elle était alors disposée à négocier d'autres conventions du même type autorisant l'échange de renseignements bancaires à des fins fiscales civiles ou pénales. Elle a écrit à plus de 80 pays pour leur proposer la conclusion de protocoles révisant l'article 26 des conventions existantes. La Belgique espère finaliser et ratifier dès que possible ces protocoles. 


\section{La part des impôts sur la consommation est assez faible}

34. Par rapport au PIB, le niveau des recettes de TVA ne se situe qu'au voisinage de la moyenne des pays de l'OCDE malgré un taux normal relativement élevé, ce qui signifie qu'il est possible d'augmenter la part de cet impôt assez peu générateur de distorsions dans l'optique de la croissance (graphique 16). En fait, la TVA ne rapporte pas autant qu'elle pourrait à cause d'une application relativement généralisée des taux réduits (près de $30 \%$ de la base d'imposition sont concernés). La presse quotidienne, les loyers et les frais de scolarité bénéficient d'un taux nul. Un taux de $6 \%$ s'applique aux produits de base et à certains services à forte intensité de main-d'œuvre (produits alimentaires, fleurs, consommation d'eau, magazines et livres, hôtellerie et camping, manifestations sportives et activités culturelles, transport de personnes et travaux de rénovation du logement), soit quelque $28 \%$ de l'assiette correspondante. Enfin, il existe un taux de $12 \%$ pour la margarine, le charbon et la télévision par câble. D'autres pays de l'OCDE appliquent eux aussi une TVA réduite à divers biens et services. Néanmoins, le rendement de la TVA en Belgique est parmi les plus faibles de la zone OCDE, en raison d'exonérations plus nombreuses que dans les autres pays (graphique 17). En tant qu'instrument de redistribution, les taux réduits ne sont pas bien ciblés car les ménages à faible revenu payent presque deux fois plus de taxes indirectes par rapport à leur revenu brut que les ménages à haut revenu, alors que les produits de consommation de base font l'objet d'une TVA réduite (Decoster et al., 2006). En réalité, les études économiques montrent clairement que les paiements forfaitaires octroyés en fonction des caractéristiques socio-économiques des ménages ou bien les aides directes ciblées sur les bas revenus sont plus efficaces en termes d'équité (Johannson et al., 2008).

35. L'augmentation des recettes fiscales tirées de la consommation permettrait d'alléger d'autres impôts. Certes, une hausse des impôts sur la consommation pourrait entraîner une augmentation des achats transfrontaliers, au détriment de l'assiette fiscale, mais la majeure partie de la population vivant à bonne distance des frontières, il devrait être possible de maintenir un certain différentiel de taux par rapport aux pays voisins. Une analyse statique montre que la suppression de tous les taux réduits et de toutes les exemptions de TVA générerait un supplément de recettes de près de 6 milliards EUR (1.9\% du PIB). Étant donné que seule une partie relativement faible de la population aurait besoin de transferts sociaux financés sur ces ressources, tandis qu'à l'heure actuelle les taux réduits d'imposition bénéficient à tous les Belges sans exception, c'est un gain de recettes de l'ordre de $1 \%$ du PIB, au bas mot, qui pourrait ainsi être mis à profit pour alléger la fiscalité dans d'autres domaines.

36. Un plus large recours aux taxes liées à l'environnement offrirait les mêmes avantages que les impôts sur la consommation. En effet, ces taxes procurent moins de recettes que dans la plupart des autres pays de l'OCDE (graphique 18), ce qui tient dans une large mesure au niveau plus faible des droits d'accise sur les carburants. De plus, le gazole est moins taxé que l'essence, alors qu'il émet plus de $\mathrm{CO}_{2}$ (et d'autres polluants), ce qui signifie que le système fiscal favorise en fait le carburant le plus nocif pour l'environnement. Dans ces conditions, il n'est donc peut-être par surprenant que les deux tiers du parc automobile se composent aujourd'hui de véhicules diesel, alors que les véhicules à essence étaient majoritaires il y a 25 ans (Conseil supérieur des finances, 2007). Souvent, ces droits d'accise évoluent au gré de la situation dans les pays voisins, pour éviter le «tourisme à la pompe » et le manque à gagner fiscal qui en découle. Cependant, les droits d'accise belges sont plus faibles que ceux des pays voisins, si l'on excepte le Luxembourg (graphique 19) ${ }^{10}$. Le budget pour 2009 prévoit un mécanisme de cliquet pour les carburants, qui fait qu'une baisse des prix du pétrole est partiellement compensée par une augmentation des droits d'accises, mais cette mesure ne tient pas compte de l'impact des différents types de carburant sur l'environnement.

10. Globalement, les droits d'accise belges sont plus faibles pour l'essence et le gazole, mais cet effet est en partie compensé par des taux de TVA légèrement plus élevés. Le niveau de taxation de l'essence et du gazole en Belgique n'en reste pas moins en deçà de ce qu'il est dans les pays voisins, le Luxembourg excepté. 
Graphique 16. Taux de TVA dans les pays membres de l'OCDE

En pourcentage
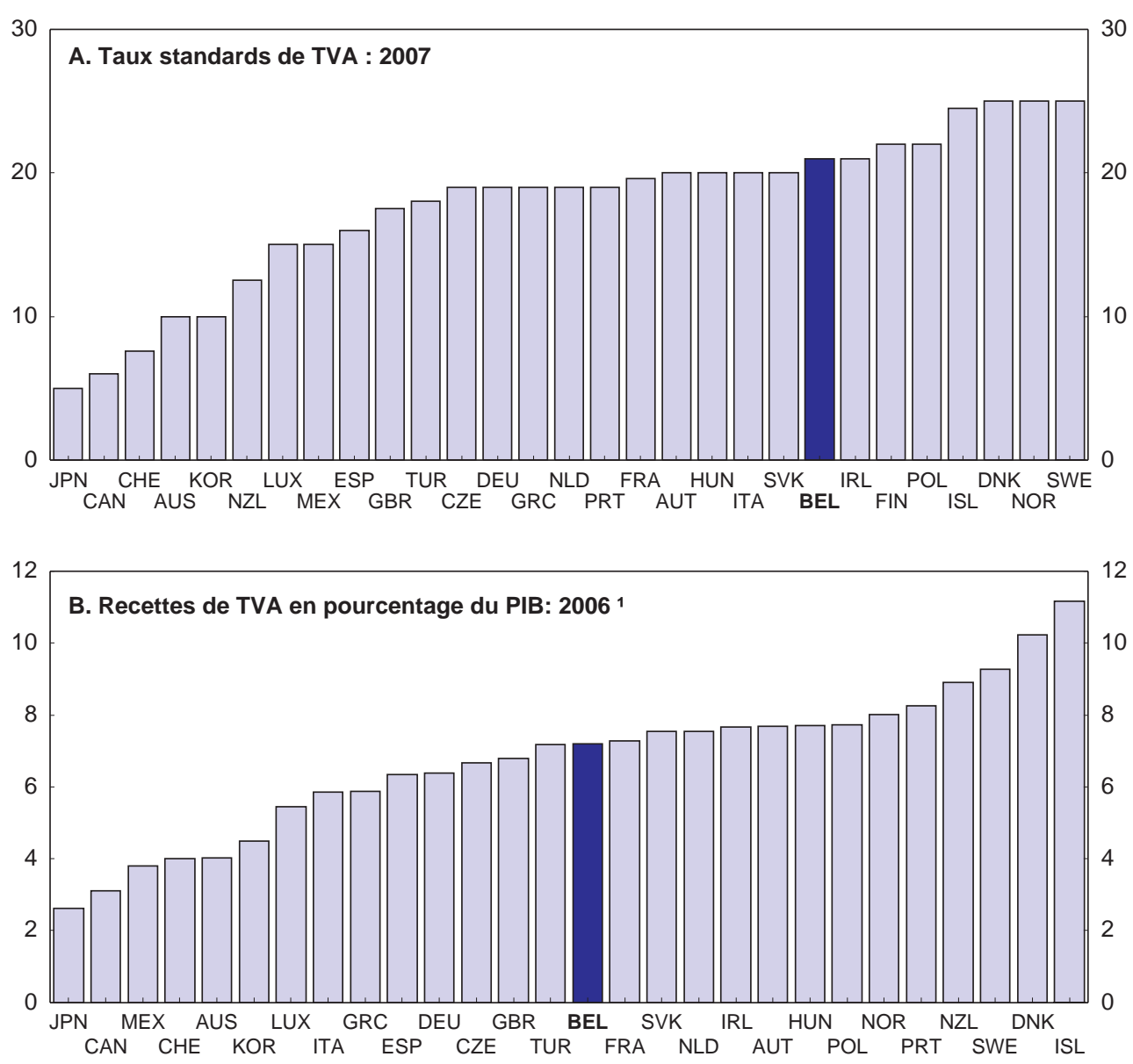

1. 2005 pour l'Australie, la Belgique, la Grèce, le Japon, l'Islande, l'Irlande, le Mexique, le Portugal et la Pologne. 2004 pour l'Italie.

Source: OCDE, Statistiques des recettes publiques et OCDE, Tendances des impôts sur la consommation.

37. Une fiscalité plus écologique des carburants serait fonction de leurs émissions de $\mathrm{CO}_{2}$ et d'autres polluants, ce qui suppose une taxation relativement plus lourde du gazole. De plus, les droits d'accise devraient être portés à des niveaux comparables à ceux des autres pays. Une simulation de l'effort que la Belgique aurait à fournir pour atteindre les objectifs de l'UE en matière de réduction des émissions de GES d'ici 2020 montre en effet qu'il faudrait une augmentation d'environ $13 \%$ des prix de l'énergie et d'environ $7 \%$ des prix des carburants par rapport au scénario de référence (Bossier et al., 2008). De plus, contrairement à la plupart des autres pays de l'UE, la Belgique taxe peu le mazout de chauffage, pourtant relativement polluant, lui appliquant un droit d'accise de seulement $4 \%$ du prix de vente (van Cauter et van Meensel, 2006). La faible taxation du mazout de chauffage se justifie par des objectifs sociaux et de redistribution, mais elle n'incite guère à investir dans des modes de chauffage moins polluants. Il existe naturellement d'autres instruments, comme les permis d'émission négociables ou le péage routier (en particulier pour les poids lourds, comme le suggérait le Conseil supérieur des finances en 2007), pour atteindre les objectifs environnementaux, mais outre les raisons écologiques, le gouvernement devrait aussi 
alourdir la fiscalité des carburants pour accroître le poids, dans le système fiscal, des impôts qui génèrent moins de distorsions comme les taxes sur la consommation.

\section{Graphique 17. Productivité de la TVA dans les pays membres de l'OCDE'}

En pourcentage, 2005

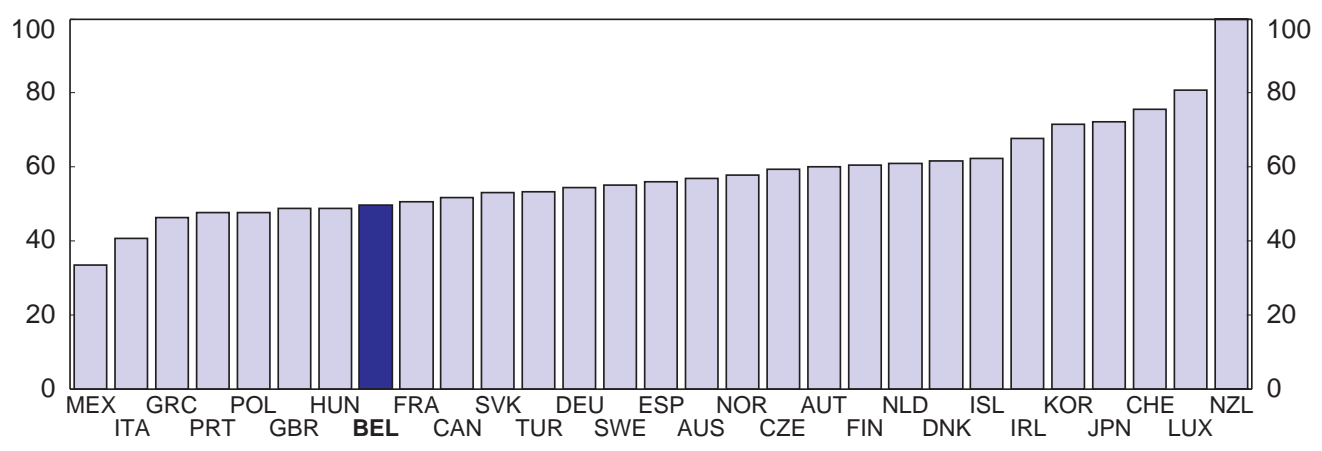

1. Une augmentation de l'indice reflète un gain d'efficience. La productivité de la TVA est égale à la part des recettes de TVA dans la consommation divisée par le taux normal, le tout exprimé en pourcentage ((recettes de TVA/consommation nationale $\times 100) /$ (taux normal de TVA)) $\times 100$. La consommation nationale comprend les traitements et salaires versés par le secteur public qui sont généralement exemptés de TVA. Les écarts de productivité de la TVA constatés entre les pays reflètent donc dans une certaine mesure des différences de taille du secteur public.

Source: OCDE (2008), Tendances des impôts sur la consommation - TVA/TPS et droits d'accise : taux, tendances et questions d'administration.

\section{Graphique 18. Recettes des taxes environnementales ${ }^{1}$}

En pourcentage du PIB

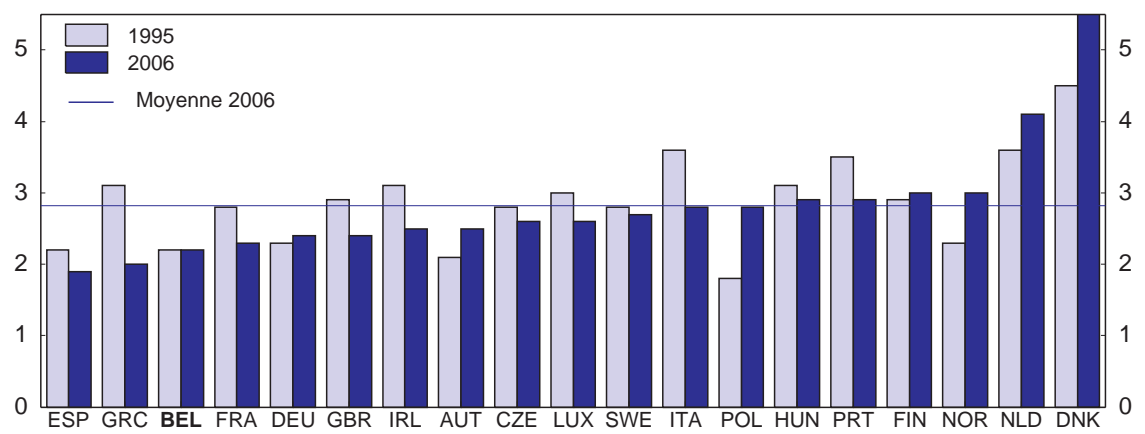

1. Recettes des taxes environnementales liées à la lutte contre la pollution.

Source : Eurostat (2008), Taxation trends in the European Union: data for the EU Member States and Norway.

38. La conception des systèmes fiscaux doit concilier plusieurs objectifs. Globalement, la capacité de générer des recettes fiscales, y compris les effets sur les bases imposables, doit être suffisante pour financer les dépenses publiques. Si l'on se projette dans l'avenir, cela signifie que toute réforme fiscale doit pouvoir s'autofinancer - ce que reconnaît également le Conseil supérieur des finances (2007). Une réforme fiscale qui ne compense pas entièrement ses propres effets n'est envisageable que si elle s'accompagne de mesures visant à réduire les dépenses publiques ou à en accroître l'efficacité. Les avantages d'une réforme fiscale qui n'a pas d'incidence sur les recettes et qui privilégie des impôts moins générateurs de distorsions peuvent donc être substantiels. Les études empiriques montrent qu'une baisse de la fiscalité du travail de $1 \%$ du PIB accompagnée d'une hausse équivalente des impôts indirects se traduit par une augmentation de la valeur ajoutée et de l'emploi dans le secteur des entreprises de respectivement $0.56 \%$ et $0.83 \%$ (Stockman 
et Lebrun, 2009 ; les résultats sont comparables dans Decoster et al., 2006). Une série de recommandations détaillées pour une réforme fiscale neutre en termes de recettes est présentée à l'encadré 4 .

\section{Graphique 19. Part des taxes dans le prix des carburants}

$\%$

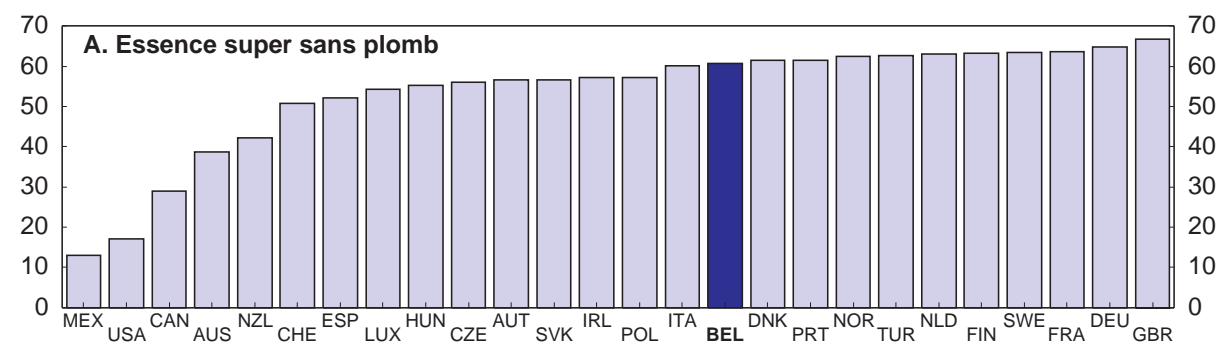

$\%$
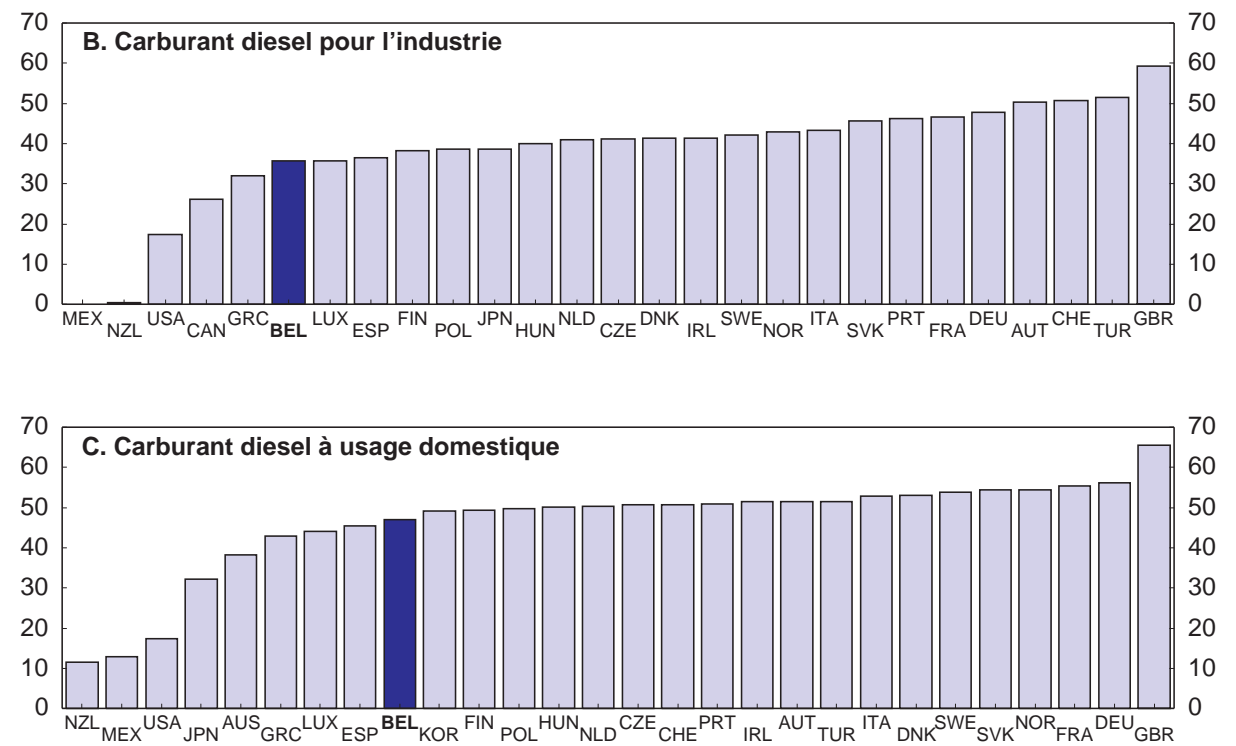

Source: OCDE (2008), Energy Prices and Taxes, Fourth Quarter 2008.

\section{Encadré 4. Recommandations pour une réforme fiscale axée sur la croissance}

\section{Privilégier les impôts qui créent moins de distorsions et l'élargissement des bases imposables}

- Le système fiscal devrait reposer davantage sur des impôts qui créent peu de distorsions, comme les taxes sur la consommation et la résidence principale, de façon à réduire la part de ceux qui en créent davantage, comme les prélèvements sur le travail et l'entreprise. La réforme doit viser à élargir les bases d'imposition afin de permettre un abaissement des taux.

\section{Rendre la taxation du travail plus propice à la croissance en stimulant l'offre et la demande de main-d'œuvre}

- Afin de supprimer les trappes à inactivité qui subsistent sur le marché du travail, il faudrait éliminer les pics des taux marginaux effectifs d'imposition.

- Pour augmenter le nombre d'heures travaillées, qui est faible par rapport aux autres pays, il faudrait abaisser les taux marginaux d'imposition les plus élevés; pour accroître le taux d'activité, il faudrait réduire le taux de prélèvement moyen sur les revenus du travail ; et pour renforcer les incitations au travail du conjoint à revenu modeste, le gouvernement devrait instaurer l'imposition séparée des couples mariés, à 
l'image de ce qui se fait dans beaucoup d'autres pays de l'OCDE.

- Afin d'élargir la base d'imposition pour pouvoir abaisser les taux, il faudrait une réduction draconienne des dépenses fiscales et des allégements structurels. Les objectifs sociaux devraient être poursuivis au moyen de mesures directes et mieux ciblées.

- Pour faire un usage plus efficace des subventions salariales et des allégements de cotisations sociales, il convient de réduire l'ampleur de ces mesures et de les limiter aux personnes difficiles à employer, par exemple aux travailleurs à bas salaire. Pendant la crise, une attention spéciale doit être accordée aux jeunes peu qualifiés qui courent le plus grand risque de quitter le marché du travail. C'est aux partenaires sociaux qu'incombe la responsabilité de sécuriser les perspectives d'emploi des autres groupes sur le marché du travail.

\section{Rendre le système d'imposition des sociétés plus favorable à l'activité des entreprises}

- Pour inciter les PME à croître jusqu'à leur niveau de production optimal, il faudrait supprimer les taux réduits de l'impôt sur les sociétés.

- Le niveau assez élevé du taux normal de l'impôt sur les sociétés devrait être abaissé de manière à faire monter le taux de rendement net d'impôt du capital investi.

- II convient d'accroître la neutralité du système vis-à-vis des différentes sources de financement en choisissant un taux d'intérêt théorique qui reflète les conditions du marché.

Accroître la neutralité du système d'imposition des revenus du capital

- Il faudrait imposer plus largement la résidence principale, en commençant par augmenter la taxation effective des loyers imputés moyennant une évaluation plus réaliste des prix des biens immobiliers. De plus, la déductibilité des paiements hypothécaires devrait être limitée aux intérêts versés sur les emprunts. Si la taxation effective des loyers imputés n'était pas relevée, il faudrait alors réduire drastiquement les possibilités de déduction des paiements hypothécaires.

- II faudrait faire en sorte que la taxation des autres instruments d'épargne soit neutre par rapport à celle de la résidence principale, notamment en éliminant progressivement les avantages fiscaux, en alignant tous les taux et en introduisant un impôt sur les gains en capital pour l'ensemble des instruments d'épargne concernés.

Faire une plus large place aux taxes sur la consommation parmi les sources de recettes fiscales

- Tous les taux de TVA devraient être portés au niveau du taux ordinaire.

- Le gouvernement devrait alourdir la taxation des carburants, en particulier du gazole, pour tenir compte des objectifs de réduction des émissions. Le péage routier est un autre instrument envisageable, en particulier pour les poids lourds. 
ECO/WKP(2009)82

\section{Bibliographie}

Bassanini, A. et R. Duval (2006), Employment Patterns in OECD Countries: Reassessing the Role of Policies and Institutions, Document de travail du département des affaires économiques, $\mathrm{n}^{\circ} 486$, OCDE, Paris.

Bodart, V., T. Lambert, P. Ledent, et V. Scourneau (2008), Réduction d'impôts et consommation des ménages en Belgique : une évaluation de l'impact de la réforme fiscale", Regards économiques, Octobre $2008, \mathrm{n}^{\circ} 62$.

Bossier, F., D. Devogelaer, D. Gusbin, et F. Verschueren (2008), «Impact of the EU Energy and Climate Package on the Belgian energy system and economy », Working Paper 21-08-Bureau fédéral du Plan, Bruxelles.

Burggraeve, K, Ph. Jeanfils, K. van Cauter, et L. van Meensel (2008), « Impact macroéconomique et budgétaire de la déduction fiscale pour capital à risque », Revue économique, Banque nationale de Belgique, septembre 2008.

van Cauter, K. et van Meensel (2006) « Le caractère redistributif des impôts et des cotisations sociales », Revue économique, Banque nationale de Belgique, Revue économique, juin 2006.

van Cauter, K., T. Stragier, I. Brumagne, L. van Meensel, et J. Claeys (2004), « Structure des recettes publiques », Revue économique, Banque nationale de Belgique, Revue économique, $2004: 2$

van den Cruyce, B. et J. Wera (2007), « Qualitative Employment Multipliers for Belgium, Results for 2000 and 2002 », Working Paper 15-07 - Bureau fédéral du Plan, Bruxelles.

Chambre des Représentants de Belgique (2007), Budget des Voies et Moyens pour l'année budgétaire 2006.

CSF (Conseil supérieur des finances) (2002), Avis sur les déductions à l'impôt des personnes physiques, Section "Fiscalité et Parafiscalité", ministère des Finances, Bruxelles.

CSF (2007), Taxation du travail, emploi et compétitivité, Section "Fiscalité et Parafiscalité", ministère des Finances, Bruxelles.

Decoster, A. et van Camp, G. (2005), « Hoe vlaks is onze tax? Is een flat tax "fair"? », Leuvense Economische Standpunten, 2005/110, Centrum voor Economische Studiën.

Decoster, A., K. de Swerdt, et G. Verbist (2006), «Indirect taxes and social policy: distributional impact of alternative financing of social security », document présenté à une conférence du SPF de la Sécurité sociale en 2006.

Decoster, A., K. de Swerdt et K. Orsini (2008), « A Belgian Flat Income Tax: Effects on Labour Supply and Income Distribution », Center for Economic Studies Discussion Paper, DPS 08.20, Louvain. 
Eugène, B. (2008), «The efficiency frontier as a method for gauging the performance of public expenditures: a Belgian case study », Banque nationale de Belgique, Research Series Working Paper $n^{\circ} 138$, septembre.

Bureau fédéral du Plan (2006) «Lastenverlagingen, loonkostenvorming en werkgelegenheid», in Loonorm, concurrentiekracht, groi en begrotingstraject, Compendium van analyses door het FPB ten behoeve van de Secretaris van de Centrale Raad voor het Bedriftsleven ("Norme salariale, compétitivité, croissance et trajectoire budgétaire", Compendium d'analyses réalisé par le BFP à l'intention du Secrétaire du Conseil central de l'Economie).

Fullerton, D., A. Leicester, et S. Smith (2008), «Environmental Taxes », NBER Working Paper, n 14197.

Gérard, M. (2009), « A quick valuation of Belgian notional interest », document non publié, Louvain School of Management.

Høj, J. (2007), «Improving incentives in tertiary education in Belgium », Document de travail du Département des affaires économiques, $\mathrm{n}^{\circ}$ 587, OCDE, Paris.

Ikkatai, D., D. Ishikawa, et K. Sasaki (2008), «Effects of the European Union Emission Trading Scheme (EU ETS) on companies: Interviews with European companies », Kyoto Institute of Economic Research, Kier Discussion paper Series, n 660, août 2008.

Immervoll, H. et M. Pearson (2009), «In-Work Benefits and making Work Pay in OECD Countries: An Update ", Document de travail de l'OCDE sur les affaires sociales, l'emploi et les migrations, OCDE, Paris, à paraître.

Jaumotte, F. (2003), « Female Labour Force Participation: Past trends and Main Determinants in OECD Countries », Document de travail du Département des affaires économiques, $\mathrm{n}^{\circ} 376, \mathrm{OCDE}$, Paris.

Jaumotte, F. et N. Pain (2005a), «From Ideas to Development: the Determinants of R\&D and Patenting », Document de travail du Département des affaires économiques, $\mathrm{n}^{\circ} 457$, OCDE, Paris.

Jaumotte, F. et N. Pain (2005b), «Innovation in the Business Sector », Document de travail du Département des affaires économiques, $\mathrm{n}^{\circ} 459$, OCDE, Paris.

Johansson, A., C. Heady, J. Arnold, B. Brys, et L. Vartia (2008), « Tax and Economic Growth », Document de travail du Département des affaires économiques, $\mathrm{n}^{\circ} 620$, OCDE, Paris.

Koskela, E. et P. Poutvaara (2008), « Outsourcing and Labor Taxation in Dual Labor Markets », CESifo Working Paper, $\mathrm{n}^{\circ} 2333$.

Martin, J.P et G. David (2001) « What works and for whom: a review of OECD countries' experiences with active labour market policies », Working Paper Series 2001:14, IFAU-Institute for Labour Market Policy Evaluation.

Mourougane, A. et L. Vogel (2008), « Speed of Adjustment to Selected Labour Market and Tax Reforms », Document de travail du Département des affaires économiques, $\mathrm{n}^{\circ}$ 647, OCDE, Paris.

OCDE (2001), Fiscalité et économie. Analyse comparative des pays de l'OCDE, Études de politique fiscale de l'OCDE, OCDE, Paris. 
OCDE (2002), Incitations fiscales en faveur de la recherche et du développement : Tendances et question, OCDE, Paris.

OCDE (2003), Statistiques des recettes publiques 1965/2002, OCDE, Paris.

OCDE (2004), La politique fiscale dans les pays de l'OCDE : Évolutions et réformes récentes, Études de politique fiscale de l'OCDE, OCDE, Paris.

OCDE (2005), Stratégie de l'OCDE pour l'Emploi : les leçons à tirer de 10 ans d'expérience. Rapport Principal, OCDE, Paris.

OCDE (2006), Refonte de l'imposition des revenus des personnes physiques, OCDE, Paris.

OCDE (2007a), Études économiques de l'OCDE : Belgique, OCDE, Paris.

OCDE (2007b), Statistiques des recettes publiques - 1965-2006, OCDE, Paris.

OCDE (2007c), Encourager l'épargne grâce à des comptes à régime fiscal préférentiel, Études de politique fiscale de l'OCDE, OCDE, Paris.

OCDE (2008), Les impôts sur les salaires 2007, OCDE, Paris.

OCDE (2009), Tax Administration in OECD and Selected Non-OECD Countries: Comparative Information Series (2008), Paris.

OCDE (2009), Études économiques de l'OCDE : Belgique, OCDE, Paris.

Oliveira Martins, J., R. Boarini, H. Strauss, C. de la Maisonneuve et C. Saadi (2007) « The Policy Determinants of Investment in Tertiary Education », Document de travail du Département des affaires économiques, $\mathrm{n}^{\circ}$ 576, OCDE, Paris.

Stockman, P. (2007), « Wage and age related employers' SSC cuts and wage subsidies in the 2007 vintage of HERMES », Federal Planning Bureau Working Paper, 12-07.

Stockman, P. et I. Lebrun (2009), « Standard Simulations for Belgium with LABMOD », LIME modelling forum meeting, Bureau fédéral du Plan.

Valenduc, C. (2003), «Effective Taxation of Household Savings in Belgium », document présenté au $59^{\text {ème }}$ congrès de l'International Institute for public finance, «Public Finance and Financial Markets ».

Valenduc, C. (2004), Les dépenses fiscales, Reflets et perspectives de la vie économique, n. ${ }^{\circ}$ 1, p. 87-104

Valenduc, C. (2005), « La progressivité de l'impôt des personnes physiques », SPF Finances, Bulletin de documentation, $\mathrm{n}^{\circ} 1$.

Valenduc, C. (2006), «Une flat tax en Belgique? Quelques éclairages sur les principes et les conséquences d'une telle réforme », Reflets et perspectives de la vie économique, 45(3), p. 63-80.

Valenduc, C. (2008), «Les incitations fiscales en faveur du logement », Les échos du logement, 2008, n. ${ }^{\circ} 2$, p. $1-24$ 
ECO/WKP(2009)82

\section{WORKING PAPERS}

The full series of Economics Department Working Papers can be consulted at www.oecd.org/eco/working_papers/

740. Improving the policy framework in Japan to address climate change (December 2009) by Randall S. Jones and Byungseo Yoo

739. Health-care reform in Japan: controlling costs, improving quality and ensuring equity (December 2009) by Randall S. Jones

738. Financial stability: overcoming the crisis and improving the efficiency of the banking sector in Japan (December 2009) by Randall S. Jones and Masahiko Tsutsumi

737. Recent Oil Price Movements- Forces and Policy Issues (December 2009) by Eckhard Wurzel, Luke Willard and Patrice Ollivaud

736. Promoting competition to strengthen economic growth in Belgium (December 2009) by Tomasz Koźluk

735. Prudential Regulation And Competition In Financial Markets (November 2009) by Rüdiger Ahrend, Jens Arnold and Fabrice Murtin

734. Keeping slovénian public finances on a sustainable path (October 2009) Pierre Beynet and Willi Leibfritz

733. Pedal to the metal: Structural reforms to boost long-term growth in Mexico and spur recovery from the crisis

(October 2009) David Haugh and Agustin Redonda

732. Achieving higher performance: Enhancing spending efficiency in health and education in Mexico (October 2009) Cyrille Schwellnus

731. Russia's long and winding road to a more efficient and resilient banking sector (October 2009) Geoff Barnard

730. How do institutions affect structural unemployment in times of crises? (October 2009) Davide Furceri and Annabelle Mourougane

729. Understanding the world trade collapse (October 2009) Calista Cheung and Stéphanie Guichard

728. Estonia and euro adoption: Small country challenges of joining EMU (October 2009) Zuzana Brixiova, Margaret H. Morgan and Andreas Wörgötter

727 Towards better schools and more equal opportunities for learning in Italy (June 2009) Romina Boarini

726. Iceland: Challenging Times for Monetary and Fiscal Policies (August 2009) Andrea De Michelis 
725. Iceland: The Financial and Economic Crisis (August 2009) David Carey

724. The role of transparency in the conduct of monetary policy (September 2009) Makoto Minegishi and Boris Cournède

723. Raising education outcomes in Greece (September 2009) Vassiliki Koutsogeorgopoulou

722. Improving the performance of the public health care system in Greece (September 2009) Charalampos Economou and Claude Giorno

721. Is there a case for price-level targeting? (August 2009) Boris Cournède and Diego Moccero

720. The challenge of restoring French competitiveness (August 2009) Rafal Kierzenkowski

719. Improving the functioning of the Slovenian labour market (August 2009) Isabell Koske

718. What drives sovereign risk premiums? An analysis of recent evidence from the Euro Area (July 2009) David Haugh, Patrice Ollivaud, and David Turner

717. The English National Health Service: an economic health check (July 2009) Peter Smith and Maria Goddard

716. Financial stability in the United Kingdom: Banking on prudence (July 2009) Philip Davis

715. Economic growth and the role of taxation- disaggregate data (July 2009) Gareth D. Myles

714. Economic growth and the role of taxation-Aggregate data (July 2009) Gareth D. Myles

713. Economic growth and the role of taxation - Theory (July 2009) Gareth D. Myles

712. The effectiveness of education and health spending among Brazilian municipalities (July 2009) Luiz de Mello and Mauro Pisu

711. The bank lending channel of monetary transmission in Brazil: A VECM approach (July 2009) Luiz de Mello and Mauro Pisu

710. How does decentralised minimum-wage setting affect unemployment and informality? The case of Indonesia

(July 2009) Margherita Comola and Luiz de Mello

709. Intergenerational social mobility in European OECD countries (July 2009) Orsetta Causa, Sophie Dantan and Åsa Johansson 